\title{
The coupling loss of a building subject to railway induced vibrations: numerical modelling and experimental measurements
}

\author{
K.A. Kuo, M. Papadopoulos, G. Lombaert, G. Degrande \\ Department of Civil Engineering, KU Leuven, Kasteelpark Arenberg 40, Box 2448, 3001 Leuven, Belgium
}

\begin{abstract}
Railway induced vibrations can be amplified or attenuated as they propagate through the foundations, floors and spans of nearby buildings. This change in vibration level, known as the building's coupling loss, is often accounted for in vibration predictions using generic, frequency independent adjustment factors. In this paper, a detailed investigation is conducted to identify methods for determining the coupling loss in new build scenarios and to investigate its dependence on various system parameters. Using the approach of separate source, propagation and receiver terms, the coupling loss is characterised as the difference between vibration velocity levels measured inside and outside the building. Three different configurations of the railway-soil-building are explored: the case where both track and building are present; the case of a new building; and the case of a new railway. In situ experiments of a building subject to excitation from nearby train passages and hammer impacts on the track are used to quantify the building response. The influence of the location of the sensors in the free field and in the building (both within a single floor and across multiple storeys) is investigated. The findings from the experimental study supports separate characterisation of the source and receiver terms, thus demonstrating that the railway can be represented by a series of on-track impacts when determining the building's coupling loss. Using this representation, a 3D building model is used to investigate the effect of dynamic soil characteristics, surface foundation type, and building geometry on the building's response to railway induced vibrations.
\end{abstract}

Keywords:

hybrid modelling, railway induced vibration, vibration transmission

\section{Introduction}

In 2017, there will be many landmark events occurring in the global rail industry. These include: the opening of the first phase of a new standard gauge railway connecting Kenya, Uganda, Rwanda, and South Sudan; the introduction of the first new Crossrail trains in London; breaking the ground for a new metro in

Email address: Kirsty.Kuo@kuleuven.be (K.A. Kuo) 
Melbourne, Australia; and the issue of a tender for construction of a Kuala Lumpur-Singapore high speed line. Concurrently, new residential and commercial buildings will be constructed next to and above existing railways. All of these projects will have a significant impact on the lives of the people living and working near the lines, with one of the major environmental issues being the noise and vibration produced by train passages. In the frequency range between 1 and $80 \mathrm{~Hz}$, vibrations cause disturbance of sensitive equipment and annoyance to people. At higher frequencies between 16 and $250 \mathrm{~Hz}$, ground borne vibrations can cause re-radiated or structure borne noise by vibrating walls and floors. Vibration level limits may vary from country to country, but regardless of location, any efforts to meet these limits require accurate predictions of railway induced vibration levels.

A state-of-the-art summary of railway vibration models is given in [1]. Examples of fully coupled forward numerical models that include the entire vehicle-track-soil-building system are few, due to the need for detailed parameter inputs and large modelling efforts. Coulier et al. [2] use a 2.5D coupled finite element - boundary element methodology to model a conventional ballasted railway track at grade and a four storey portal frame founded on embedded strip foundations, noting that source-receiver interaction effects are observed for a dimensionless source-receiver distance (using the Rayleigh wavelength) smaller than six. More common is a decoupled approach where the vehicle-track response is computed first to obtain the dynamic loads acting on the soil surface or a tunnel invert, and then these loads are applied in order to obtain the free field and building response. Examples of this include Kouroussis et al. [3] who model a private residence next to a tramway using a coupled lumped mass model and a finite/infinite element model; Stupazzini and Paolucci [4] use a beam on elastic foundation to calculate the loading that is applied to a tunnel-soil-structure model that employs spectral elements. A further degree of decoupling is used by Rücker and Auersch [5], where a multibody vehicle model and beam-on-support track model are used to calculate the dynamic train loads, which are propagated through the soil using the superposition of approximate transfer functions. The transfer from soil to building is then accounted for using a wall-floor building model with a spring-damper soil element. A similar three-step approach is used by Vogiatzis [6], who calculates vibration levels on a tunnel-soil interface using a FE model, propagates the vibrations through the soil using analytical equations, and then uses empirical formulae to estimate the propagation of vibrations through the building.

Amongst vibration consultants, these empirical formulae that account for vibration attenuation through the foundation and building are a popular and commonly implemented approach. These formulae have been generated based on an understanding of how a building will respond to excitation from a nearby railway, obtained via experimental methods. For example, the experimental study by Xia et al. [7] on a six-storey masonry building near the Beijing-Guangzhou railway found the following trends: (1) increasing vertical velocity levels in the building with increasing train speed; (2) larger floor vibration levels for freight trains compared to passenger trains; (3) fluctuating vertical velocity levels with floor elevation; and (4) indoor floor 
vibrations lower than outdoor ground vibrations, with a maximum average difference of approximately $10 \mathrm{~dB}$ in the vertical direction. Hood et al. 8] derive a deliberately conservative empirical approach based on the analysis of more than 3000 measurements, where the vertical vibration dose values (VDV) at mid-span on the ground floor of brick-built residential properties with strip foundations are twice those measured on the ground immediately outside the property of interest. For the first floor and above, the VDV is considered to be four times the free field level outside the property. Madshus et al. [9] define a building amplification factor for predicting the most unfavourable vibration levels in common Norwegian wooden buildings on soft ground. This building amplification factor is multiplied by the basic vibration function and the track quality factor to obtain a frequency weighted RMS velocity value. Based on measurements, single storey buildings have a mean amplification factor of 1.3 and standard deviation of 1.0, and two storey buildings have a mean amplification factor of 1.9 and standard deviation of 1.2. Ground conditions do not significantly affect the amplification factor. The widely used Federal Railroad Administration (FRA) approach [10] defines three adjustment factors that are applied to the free field vibration velocity level: (a) those that represent the change in the incident ground-surface vibration due to the presence of the building foundation, (b) the attenuation of vibration as it travels from foundation to the upward floors, assumed at a rate of 1 to $2 \mathrm{~dB}$ per floor, and (c) amplification of approximately $6 \mathrm{~dB}$ in the frequency range of the fundamental floor resonances (15-20 Hz for wood-frame, 20-30 Hz for reinforced concrete slabs). For (a), zero correction is applied when estimating basement floor vibration or vibration of at-grade slabs, and frequency dependent attenuation ranging from $0-15 \mathrm{~dB}$ is prescribed for masonry buildings on piles and spread footings.

A recent development in predicting railway vibration levels involves the use of hybrid models that combine field measurements with state-of-the-art numerical techniques, thus partially avoiding the need for simplifying modelling assumptions and detailed parameter identification. A hybrid modelling formulation for free field vibrations is described in Kuo et al. [11], which uses separate source and propagation terms that can be quantified using either numerical modelling or field measurements. To extend this modelling approach to encompass the entire vehicle-track-soil-building system, a receiver term can be included that characterises the dynamic interaction of a building with railway induced vibrations. This receiver term is similar to the empirical formulae described in the previous paragraph in that it describes the same physical process of vibration transmission through a building and its foundations. It differs in that it is quantified in one-third octave band vibration velocity levels using numerical models or field measurements, whereas empirical formulae are generally frequency independent. In this paper, a detailed investigation of this receiver term, referred to as the building's "coupling loss", is conducted, with particular emphasis on how it can be defined and measured in new build scenarios where the railway or the building have not yet been constructed. Following a description of the hybrid model framework in section 2, three different expressions that characterise the dynamic interaction of a building with railway induced vibrations are introduced in section 3. These expressions are evaluated and compared using field measurements in section 4. In section 5. 
a parametric study that investigates the effect of dynamic soil characteristics, surface foundation type, and building geometry on the building's coupling loss is presented. It should be noted that although the theory, modelling and measurements presented in the paper could enable coupling loss values to be calculated for three orthogonal directions, results are only presented for the vertical direction, as this is the primary direction of interest for railway induced vibrations [10]. Horizontal vibrations would be of interest if the building contained sensitive equipment or if structural damage were an issue, although the latter is less likely.

\section{Hybrid model framework}

The hybrid model adopts the general framework recommended in the ISO 14837-1 standard [12], where the magnitude of the quasi-stationary response $A(f)$ in a building during a train passage is expressed as the product of three terms:

$$
A(f)=S(f) P(f) R(f)
$$

where $S(f)$ represents the source strength, $P(f)$ accounts for the propagation path, and $R(f)$ characterises the receiver. All three terms are a function of frequency $f$ and can be considered to be uncoupled only in some situations. To obtain the vibration velocity level at a given frequency, each of these terms should be calculated at the same frequency, which is strictly speaking not valid for moving sources due to the Doppler effect [13].

Hybrid models can be implemented using any prescribed method of determining the source, propagation and receiver terms. The empirical procedure proposed by the FRA [10] is one such method and is expressed as:

$$
\mathrm{L}_{\mathrm{v}}\left(\mathbf{x}_{\mathrm{b}}\right)=\mathrm{L}_{\mathrm{F}}\left(\mathbf{X}, \mathbf{x}_{1}\right)+\mathrm{TM}_{\mathrm{L}}\left(\mathbf{X}, \mathbf{x}_{1}\right)+\mathrm{C}_{\mathrm{b}}\left(\mathbf{x}_{1}, \mathbf{x}_{\mathrm{b}}\right)
$$

where $\mathbf{X}$ is a vector that collects all of the source points, located on the rail heads. The term $\mathrm{L}_{\mathrm{v}}\left(\mathbf{x}_{\mathrm{b}}\right)$ is the vibration velocity level at the receiver point $\mathbf{x}_{\mathrm{b}}$ in the building, and is measured in decibels at onethird octave band intervals, resulting in a summation of the source, propagation and receiver terms, rather than the product as per equation (11). The term $\mathrm{L}_{\mathrm{F}}\left(\mathbf{X}, \mathbf{x}_{1}\right)$ is the equivalent force density level; the term $\mathrm{TM}_{\mathrm{L}}\left(\mathbf{X}, \mathbf{x}_{1}\right)$ is the line source transfer mobility; and the term $\mathrm{C}_{\mathrm{b}}\left(\mathbf{x}_{1}, \mathbf{x}_{\mathbf{b}}\right)$ is the building's coupling loss. The receiver points $\mathbf{x}_{1}$ and $\mathbf{x}_{\mathrm{b}}$ are located at some point on the ground surface, and at some point inside the building, respectively. Source and receiver locations are illustrated in figure 1.

The omission of the building's coupling loss term from equation 2 gives the expression for the vibration velocity level in the free field in the presence of a building:

$$
\mathrm{L}_{\mathrm{v}}\left(\mathbf{x}_{1}\right)=\mathrm{L}_{\mathrm{F}}\left(\mathbf{X}, \mathbf{x}_{1}\right)+\mathrm{TM}_{\mathrm{L}}\left(\mathbf{X}, \mathbf{x}_{1}\right)
$$




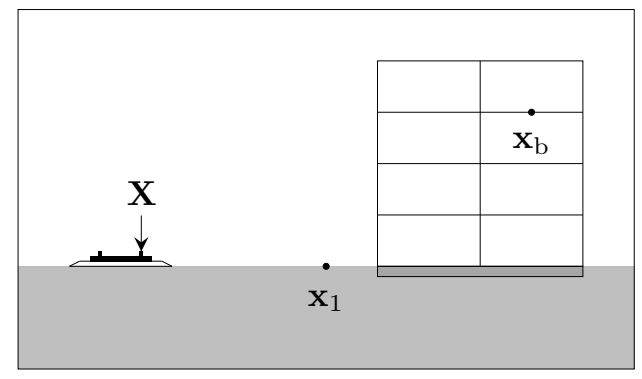

Figure 1: Position of the source and receiver points for the FRA procedure when both railway and building are present.

which includes the effect of soil-structure interaction. Rearranging this equation gives a method of determining the excitation force, represented by the equivalent force density level $\mathrm{L}_{\mathrm{F}}\left(\mathbf{X}, \mathbf{x}_{1}\right)$ :

$$
\mathrm{L}_{\mathrm{F}}\left(\mathbf{X}, \mathbf{x}_{1}\right)=\mathrm{L}_{\mathrm{v}}\left(\mathbf{x}_{1}\right)-\mathrm{TM}_{\mathrm{L}}\left(\mathbf{X}, \mathbf{x}_{1}\right)
$$

This excitation force term represents the equivalent fixed line source that results in the same vibration velocity level as the train passage. The force density level depends on both the actual force generated at the wheel/rail interface and the dynamic characteristics of the transit structure (that is, the track, subgrade and soil).

The vibration propagation from the track, through the soil to the receiver point on the soil surface is contained within the line source transfer mobility term $\mathrm{TM}_{\mathrm{L}}\left(\mathbf{X}, \mathbf{x}_{1}\right)$. This involves the superposition of point source transfer mobility levels $\operatorname{TM}_{\mathrm{P}}\left(\mathbf{X}_{k}, \mathbf{x}_{1}\right)$ for a series of $n$ equidistant source points with spacing $h$ :

$$
\mathrm{TM}_{\mathrm{L}}\left(\mathbf{X}, \mathbf{x}_{1}\right)=10 \log _{10}\left[h \sum_{k=1}^{n} 10^{\frac{\mathrm{TM}_{\mathrm{P}}\left(\mathbf{x}_{k}, \mathbf{x}_{1}\right)}{10}}\right]
$$

The receiver term $\mathrm{C}_{\mathrm{b}}\left(\mathbf{x}_{1}, \mathbf{x}_{\mathrm{b}}\right)$ represents the building's coupling loss. The FRA approach computes this term as a combination of dimensionless adjustment factors used to account for ground-building foundation interaction and amplification or attenuation of vibration amplitudes as vibration propagates through buildings (see section 1). These adjustment factors are added to the ground-surface vibration at location $\mathbf{x}_{1}$ near the building, to estimate the response inside the building, at location $\mathbf{x}_{\mathrm{b}}$. We will now elaborate the definition of the receiver term $\mathrm{C}_{\mathrm{b}}\left(\mathbf{x}_{1}, \mathbf{x}_{\mathrm{b}}\right)$ for three different configurations of the railway-soil-building: the reference case, where both track and building are present; the case of a new building; and the case of a new railway.

\section{Characterising the building coupling loss}

\subsection{Case 1: Reference; both railway and building are present}

When both a railway and building are present, the coupling loss of the building can be quantified as the difference in vibration velocity level $\mathrm{L}_{\mathrm{v}}\left(\mathbf{x}_{\mathrm{b}}\right)$ at some point $\mathbf{x}_{\mathrm{b}}$ in the building, and $\mathrm{L}_{\mathrm{v}}\left(\mathbf{x}_{1}\right)$ at some point $\mathbf{x}_{1}$ 
on the ground surface with the building present. This is illustrated in figure 2 and expressed as:

$$
\mathrm{C}_{\mathrm{b}}\left(\mathrm{x}_{1}, \mathbf{x}_{\mathrm{b}}\right)=\mathrm{L}_{\mathrm{v}}\left(\mathbf{x}_{\mathrm{b}}\right)-\mathrm{L}_{\mathrm{v}}\left(\mathbf{x}_{1}\right)
$$

This definition of the building's coupling loss is regarded as the reference expression for the receiver term and is referred to as Case 1. The vibration velocity levels can either be determined using field measurements of the vibrations produced during a train passage, or they can be calculated numerically using a train-tracksoil-building model.

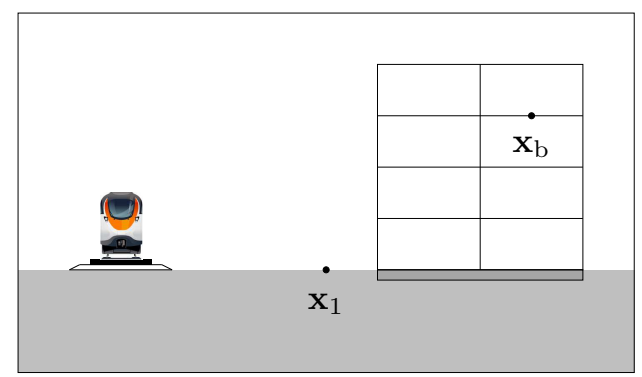

Figure 2: Case 1 coupling loss determined using vibration velocity levels at some point $\mathbf{x}_{\mathrm{b}}$ in the building and at some point $\mathbf{x}_{1}$ on the ground surface.

The coupling loss value will depend on the positions of $\mathbf{x}_{1}, \mathbf{x}_{\mathrm{b}}$ relative to the track; the closer $\mathbf{x}_{1}$ is to the building, the more the vibration level $\mathrm{L}_{\mathrm{v}}\left(\mathrm{x}_{1}\right)$ will be influenced by the presence of the building. Moreover, locating the receiver point $\mathbf{x}_{1}$ far from the building will result in a coupling loss that includes a greater contribution (proportionally) from the propagation path. The position $\mathbf{x}_{\mathrm{b}}$ can also vary within the building; the location $\mathbf{x}_{\mathrm{b}}$ will determine whether the receiver term incorporates effects such as floor-to-floor attenuation and floor resonances.

The reference definition of the building's coupling loss can be further elaborated by expressing the two vibration velocity levels as the sum of excitation force and propagation path terms. For example, writing

$$
\mathrm{L}_{\mathrm{v}}\left(\mathbf{x}_{\mathrm{b}}\right)=\mathrm{L}_{\mathrm{F}}\left(\mathbf{X}, \mathbf{x}_{\mathrm{b}}\right)+\mathrm{TM}_{\mathrm{L}}\left(\mathbf{X}, \mathbf{x}_{\mathrm{b}}\right)
$$

and incorporating the expression for $\mathrm{L}_{\mathrm{v}}\left(\mathrm{x}_{1}\right)$ in equation (3), results in

$$
\mathrm{C}_{\mathrm{b}}\left(\mathbf{x}_{1}, \mathbf{x}_{\mathrm{b}}\right)=\mathrm{TM}_{\mathrm{L}}\left(\mathbf{X}, \mathbf{x}_{\mathrm{b}}\right)-\mathrm{TM}_{\mathrm{L}}\left(\mathbf{X}, \mathbf{x}_{1}\right)+\mathrm{L}_{\mathrm{F}}\left(\mathbf{X}, \mathbf{x}_{\mathrm{b}}\right)-\mathrm{L}_{\mathrm{F}}\left(\mathbf{X}, \mathbf{x}_{1}\right)
$$

By assuming the two force density terms to be equal (further discussion of this follows), the building coupling loss is written as:

$$
\mathrm{C}_{\mathrm{b}}^{*}\left(\mathbf{x}_{1}, \mathbf{x}_{\mathrm{b}}\right)=\mathrm{TM}_{\mathrm{L}}\left(\mathbf{X}, \mathbf{x}_{\mathrm{b}}\right)-\mathrm{TM}_{\mathrm{L}}\left(\mathbf{X}, \mathbf{x}_{1}\right)
$$

where $\operatorname{TM}_{\mathrm{L}}\left(\mathbf{X}, \mathbf{x}_{\mathrm{b}}\right)$ and $\mathrm{TM}_{\mathrm{L}}\left(\mathbf{X}, \mathbf{x}_{1}\right)$ are the line source transfer mobilities measured at some point $\mathbf{x}_{\mathrm{b}}$ in the building and at some point $\mathbf{x}_{1}$ on the ground surface in the presence of the building, respectively. The 
asterisk in equation (9) indicates that this is an approximate expression based on the assumption of equivalent force densities. The source points used to determine the line source transfer mobilities are collected in the vector $\mathbf{X}$ and are located at the rail heads, thus this calculation of the building's coupling loss does not require the passage of a train. This makes it a useful means of measuring the coupling loss in the field, provided the excitation applied at $\mathbf{X}$ is sufficiently large to produce a measurable building response. It also simplifies a numerical computation of the building response by removing the need for a vehicle model and characterisation of the wheel-rail unevenness.

One further approximation of the building's coupling loss, which makes use of source points $\mathbf{X}_{1}$ located at alternative locations away from the rail heads, is:

$$
\mathrm{C}_{\mathrm{b}}^{*}\left(\mathbf{x}_{1}, \mathbf{x}_{\mathrm{b}}\right)=\mathrm{TM}_{\mathrm{L}}\left(\mathbf{X}_{1}, \mathbf{x}_{\mathrm{b}}\right)-\mathrm{TM}_{\mathrm{L}}\left(\mathbf{X}_{1}, \mathbf{x}_{1}\right)
$$

The source points could, for example, be on the sleeper, or on the soil's surface adjacent to the track. This expression has the advantage of avoiding access to the rail heads while determining the building's coupling loss during a measurement campaign, or, alternatively, using a numerical model that does not include all or part of a track. The use of source points located closer to the building rather than on the rail heads should serve to increase the signal-to-noise ratio recorded by the building sensors during a measurement campaign.

The assumption of equivalent force density terms is as yet unvalidated, but a supporting case can be made for it by considering some recent findings. The force density level has been shown to be dependent on the dynamic axle loads [14], and Coulier et al. 22] have shown that dynamic axle loads can be calculated with reasonable accuracy using an uncoupled strategy in which through-soil coupling of the building and the track is disregarded. However, the force density levels calculated during a measurement campaign at Lincent, Belgium [11] were shown to depend on distance from the track. In section 4 of this paper it will be shown that the experimental force density levels calculated at a site in Heverlee, Belgium, using an average of multiple train passages are relatively insensitive to measurement location. It is feasible that when $\mathbf{x}_{1}$ is located at a similar distance from the track as $\mathbf{x}_{\mathrm{b}}$ (i.e. alongside the building), and the building is sufficiently far from the track to reduce track-building coupling, $\mathrm{L}_{\mathrm{F}}\left(\mathbf{X}, \mathbf{x}_{\mathrm{b}}\right)=\mathrm{L}_{\mathrm{F}}\left(\mathbf{X}, \mathbf{x}_{1}\right)$ should hold.

\subsection{Case 2: Railway is present, no building at the site}

When a building is planned but not built at the site of interest, the coupling loss can be defined in reference to a vibration velocity level $\mathrm{L}_{\mathrm{v}}\left(\mathrm{x}^{\prime}\right)$ due to a train passage that is measured or calculated at a point $\mathbf{x}^{\prime}$ in the free field (i.e. in the absence of a building). This is illustrated in figure 3 and expressed in:

$$
\mathrm{C}_{\mathrm{b}}\left(\mathrm{x}^{\prime}, \mathrm{x}_{\mathrm{b}}\right)=\mathrm{L}_{\mathrm{v}}\left(\mathrm{x}_{\mathrm{b}}\right)-\mathrm{L}_{\mathrm{v}}\left(\mathrm{x}^{\prime}\right)
$$

The points of $\mathbf{x}^{\prime}$ and $\mathbf{x}_{\mathrm{b}}$ may or may not be located at equal distances from the track. Determining the vibration velocity levels at $\mathbf{x}^{\prime}$ and $\mathbf{x}_{\mathrm{b}}$ requires the passage of a train. This scenario, where a building does not 
yet exist at the site of interest, is referred to as Case 2. This definition of the building response characterises the influence of dynamic soil-structure interaction (SSI) on the building response, and vice versa. Whilst pre- and post- construction field measurements could, in theory, be used to obtain a measured value of the building response according to this definition, a more practical implementation would involve the use of a numerical model of the (future) building.

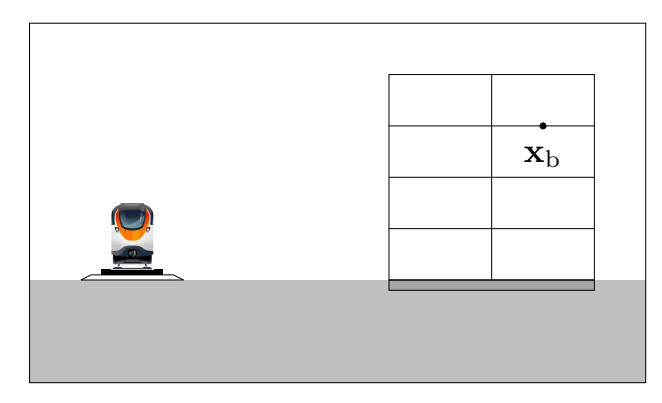

(a)

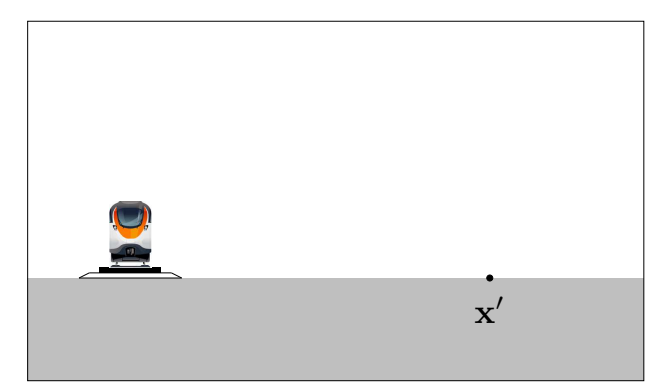

(b)

Figure 3: Case 2 coupling loss determined using vibration velocity levels at (a) some point in the building $\mathbf{x}_{\mathrm{b}}$, and at (b) some point in the free field $\mathbf{x}^{\prime}$ at the site of interest.

Following a similar procedure to that for the reference case, the assumption of equivalent force density terms can be invoked to obtain the following definitions of the receiver term:

$$
\mathrm{C}_{\mathrm{b}}^{*}\left(\mathbf{x}^{\prime}, \mathbf{x}_{\mathrm{b}}\right)=\mathrm{TM}_{\mathrm{L}}\left(\mathbf{X}, \mathbf{x}_{\mathrm{b}}\right)-\mathrm{TM}_{\mathrm{L}}\left(\mathbf{X}, \mathbf{x}^{\prime}\right)
$$

and

$$
\mathrm{C}_{\mathrm{b}}^{*}\left(\mathbf{x}^{\prime}, \mathbf{x}_{\mathrm{b}}\right)=\mathrm{TM}_{\mathrm{L}}\left(\mathbf{X}_{1}, \mathbf{x}_{\mathrm{b}}\right)-\mathrm{TM}_{\mathrm{L}}\left(\mathbf{X}_{1}, \mathbf{x}^{\prime}\right)
$$

As per the reference case, these expressions remove the requirement of a train passage by replacing the source excitation with impacts at the railheads or at alternative source locations, respectively.

\subsection{Case 3: Building is present, no track at the site}

When a railway is planned but not built at the site of interest, or has only been partially constructed, an approximate expression for the receiver term can be defined that is independent of the presence of a track:

$$
\mathrm{C}_{\mathrm{b}}^{*}\left(\mathbf{x}_{1}, \mathbf{x}_{\mathrm{b}}\right)=\mathrm{TM}_{\mathrm{L}}\left(\mathbf{X}_{1}, \mathbf{x}_{\mathrm{b}}\right)-\mathrm{TM}_{\mathrm{L}}\left(\mathbf{X}_{1}, \mathbf{x}_{1}\right)
$$

where $\mathbf{X}_{1}$ is located at the site of the future railway - whether the positions of $\mathbf{X}_{1}$ be on the ground surface, on a surface foundation or on a partially constructed track. This is illustrated in figure 4 , and this scenario, where a railway does not yet exist at the site of interest, is referred to as Case 3 .

This building coupling loss is the same as that obtained for the reference case under the assumption of equivalent force densities and alternative source locations (equation (10)). It has great practical value, as it 


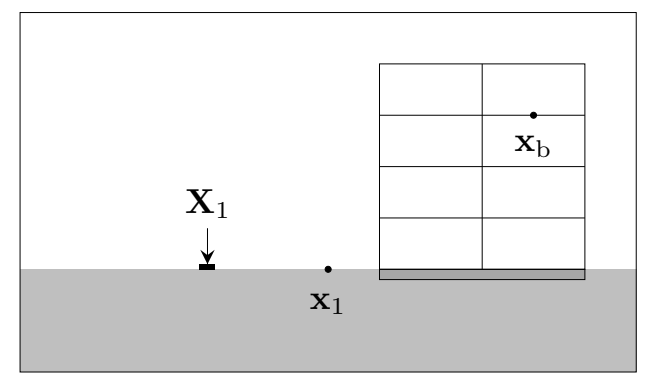

Figure 4: Case 3 coupling loss determined using excitation at $\mathbf{X}_{1}$ and the response at some point(s) in the building $\mathbf{x}_{\mathrm{b}}$ and on the ground surface $\mathbf{x}_{1}$.

is relatively straightforward to quantify it using either experimental measurements or a numerical model of the soil and building.

\section{Coupling loss evaluation using measurements}

\subsection{Experimental setup}

To evaluate and compare the Case 1 coupling loss values determined using vibrations produced during a train passage with the approximate Case 1 coupling loss values determined using vibrations produced by impacts, an extensive field measurement campaign was carried out in October 2016 at a site located on the railway line L1390 between Leuven and Ottignies, Belgium. The site layout is not the same as that used in the numerical study in section 5 and the measurement results are therefore not intended to serve as a model validation, but rather as a separate study. The railway line consists of two classical ballasted tracks with continuously welded UIC 60 rails that are supported every $0.60 \mathrm{~m}$ by resilient studded rubber pads on a prestressed monoblock concrete sleeper. Both freight trains and passenger trains of type Desiro ML AM08, built by Siemens, operate on the line.

Located at a distance of $33 \mathrm{~m}$ from the nearside track, 'Blok D' is a three-storey building with a belowground basement, and is currently being used for administrative services. It is shown in figure 5 The building is a reinforced concrete and masonry construction with internal partition walls. Each floor has an area of $350 \mathrm{~m}^{2}$, and the building is connected via a single storey passageway to adjacent buildings.

During the measurement campaign, the dynamic response in the free field and the building was measured simultaneously over a period of seven days, which resulted in a database of over 500 freight and passenger train passages. The free field vibration measurements were recorded using eighteen high sensitivity uniaxial seismic accelerometers (PCB393 series) and two GeoSIG GMSplus units, measuring accelerations along three measurement lines located perpendicular to the track, as shown in figure 6. On line 1, both the vertical $(z)$ and horizontal $(x)$ accelerations were measured. On line 2, only the vertical $(z)$ accelerations were measured. On line 3 , the accelerations in the vertical $(z)$ and the two orthogonal horizontal directions $(x$ 


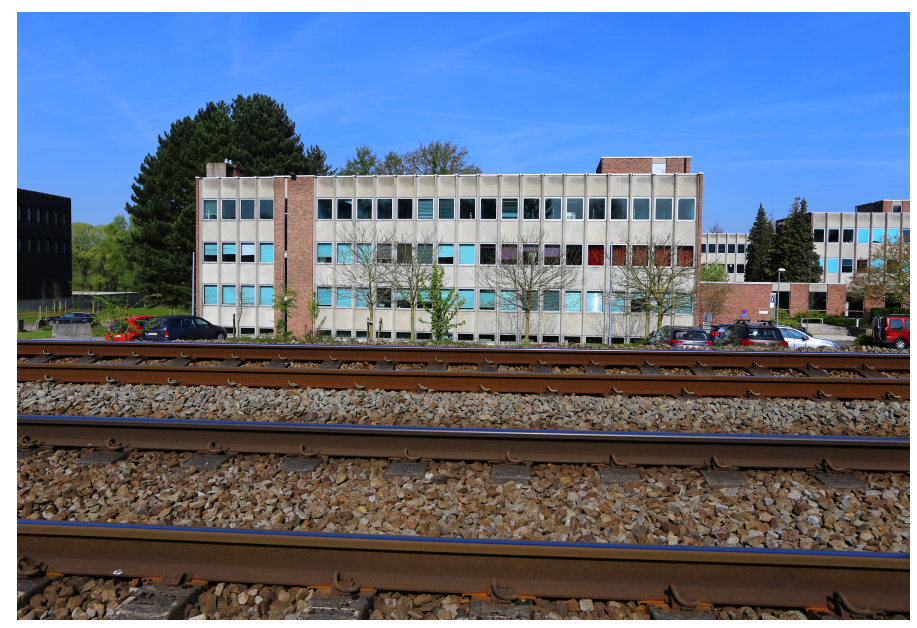

Figure 5: The Blok D building is a three-storey building with below-ground basement, located approximately $30 \mathrm{~m}$ from the railway track.

and $y$ ) were measured. The dynamic response of the building was measured at four locations on each level of the building (basement, ground floor, first floor and second floor) using twelve GeoSIG GMS-18 units, three GeoSIG GMSplus units and one high sensitivity uniaxial seismic accelerometer. Figure 7 shows the four measurement locations on the first floor of Blok D; these measurement locations were mirrored for each floor. The sensor designation used here has two numbers to denote the floor level $(91,00,01,02$ for basement through to second floor), followed by three numbers to denote the location within the floor space, then followed by the measurement direction(s) $(x, y, z)$. The Nyquist frequency for the PCB accelerometers is $500 \mathrm{~Hz}$, and the Nyquist frequency for the GeoSIGs is $100 \mathrm{~Hz}$. The two measurement systems were time-synchronised using simultaneous acquisition of a signal measured on the second floor of the building.

The train passage events are isolated using a trigger on a high sensitivity accelerometer installed on a sleeper to obtain an event window of $131 \mathrm{~s}$. A fifth order Butterworth filter is applied to smooth the noise in the first $1 \%$ and final $1 \%$ of the time window. A third order Chebyshev filter with high pass frequency $4 \mathrm{~Hz}$, low pass frequency of $449 \mathrm{~Hz}$ for PXI data and $99 \mathrm{~Hz}$ for GMS data, and a ripple of $0.1 \mathrm{~dB}$ is applied to avoid drifting of the signal. The velocity is then computed by integration of the acceleration using a trapezium rule. The time period $T_{2}$ as defined by the German DIN standard [15] is used to identify the stationary part of the velocity response for each event, on each channel. The narrow band frequency content of the signal within this time period is used to calculate the RMS value of the velocity $v_{\text {RMS } m}$ in the $m$ th one-third octave band, which can then be used to obtain the vibration velocity level as per:

$$
\mathrm{L}_{\mathrm{v} m}=20 \log _{10}\left[v_{\mathrm{RMS} m}\right]-\mathrm{L}_{\mathrm{v} 0}
$$

where $\mathrm{L}_{\mathrm{v} 0}=20 \log _{10}\left[v_{0}\right]$ is the reference level calculated using a reference velocity of $v_{0}=10^{-8} \mathrm{~m} / \mathrm{s}$.

In a second set of measurements, transfer functions were obtained using excitations from an impact 


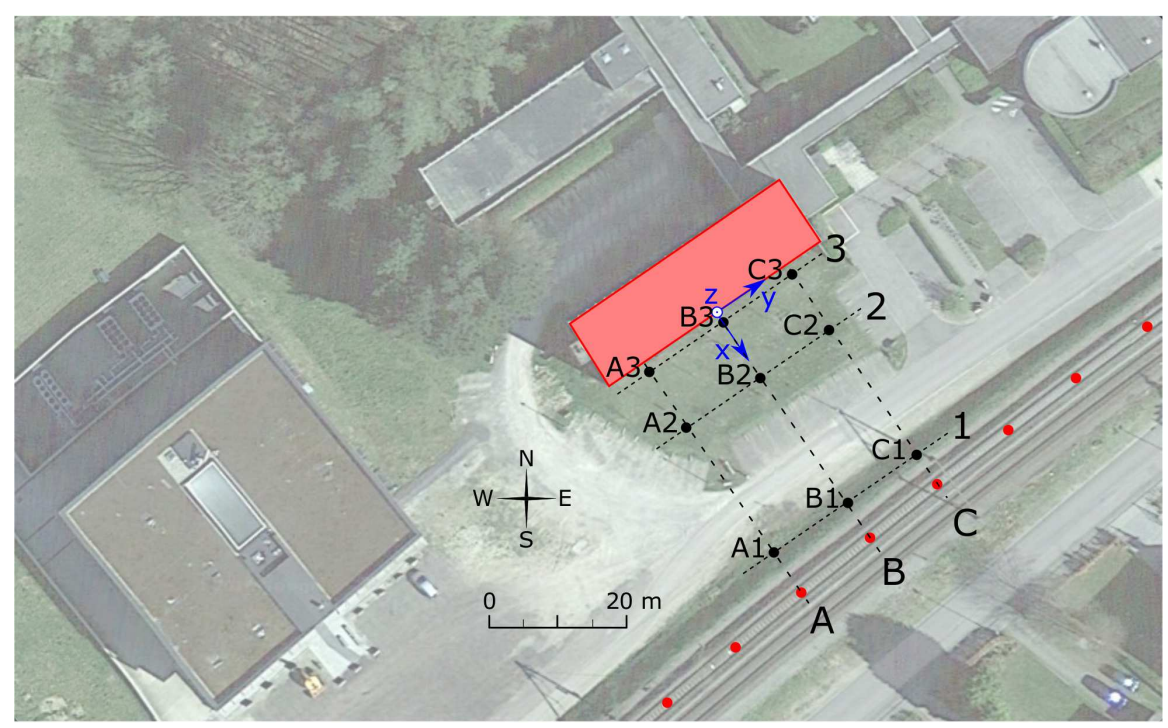

Figure 6: Free field measurement locations (black dots). The measurement lines A, B, and C correspond to $y=-12 \mathrm{~m}, y=0 \mathrm{~m}$ and $y=12 \mathrm{~m}$, respectively. The measurement lines 1,2 , and 3 correspond to $x=32 \mathrm{~m}, x=12 \mathrm{~m}$, and $x=1 \mathrm{~m}$, respectively. Eight of the seventeen hammer impact locations are also shown (red dots).

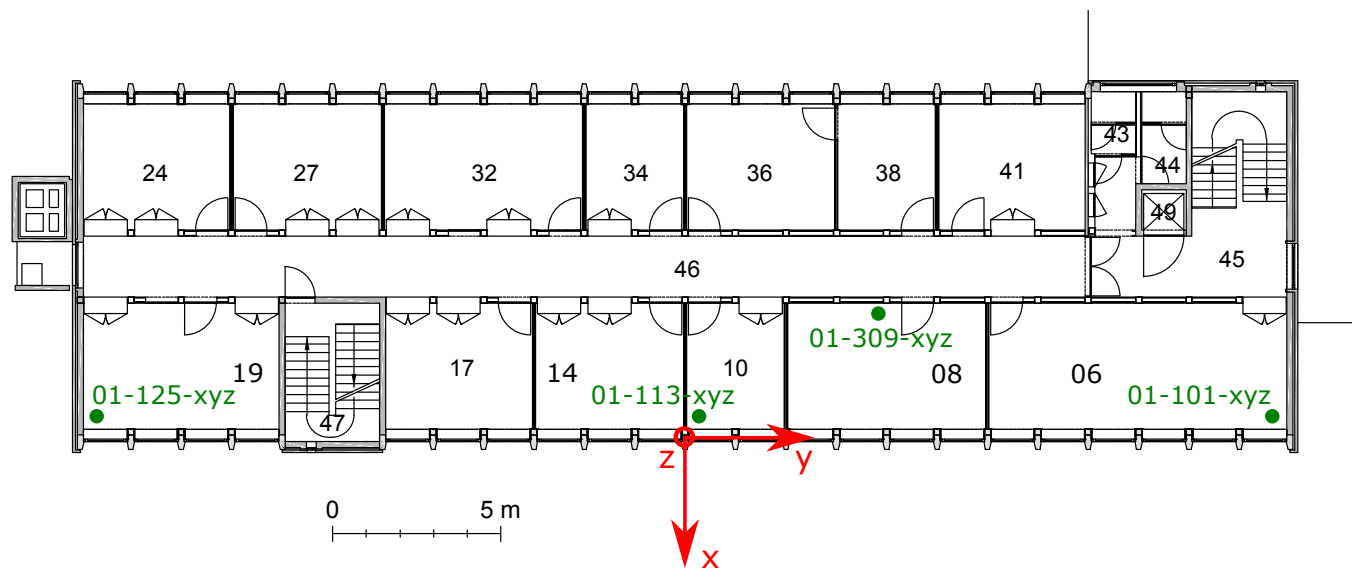

Figure 7: Measurement locations at the first floor of Blok D. 
hammer with a mass of $5.5 \mathrm{~kg}$ and a soft tip equipped with a force sensor (PCB 086D50). Hammer impacts were applied to sleepers located every $12 \mathrm{~m}$ along the track, over a total distance of $196 \mathrm{~m}$. The response in the free field and in the building is determined by integrating the acceleration time signals to obtain the velocity response, and computing the mobility between each source and receiver using the force history. Then the average transfer function is calculated using over 100 hammer impacts at each impact location.

\subsection{Results}

\subsubsection{Coupling loss using train passages}

Of the recorded train passages, 117 are three-carriage passenger trains of type Desiro ML AM08 travelling towards Leuven on the nearside track in a speed range of 77-100 km/h. The measured vertical vibration velocity in one-third octave bands during one of these passages at various distances from the track and at various floors in the building is shown in figure 8 . As the distance between the surface measurement point and the railway increases, the vibration level attenuates with distance from the track due to a combined effect of geometrical spreading and material damping in the soil. The effect of changing the height of the measurement point location within the building, as seen in figure $8(\mathrm{~b})$, is more pronounced at frequencies greater than $25 \mathrm{~Hz}$, but there is no clear trend of vibration attenuation with floor height. This corresponds with the findings of Xia et al. 7], who observed fluctuating vertical velocity levels with floor elevation, but runs counter to the FRA recommendation of an adjustment factor of 1-2 dB attenuation per floor. The vibration levels within the building are, on the whole, smaller than those measured directly outside the building. This again concurs with the general trend observed by Xia et al. [7]. (Note that the $10 \mathrm{~dB}$ difference between inside and outside levels quoted by Xia et al. is not directly comparable to the results presented here, as Xia et al. use the maximum of the running RMS velocity calculated using a $1 \mathrm{~s}$ interval whereas our results use the RMS velocity values calculated over period $T_{2}$ as per the DIN standard.) The FRA approach proposes zero correction when estimating basement floor vibration, which is not supported by these results.

By collating the data from the 117 train passages, average vibration velocity levels can be determined. Figure 9 shows the average vertical vibration velocity in one-third octave bands at various distances from the track and at various floors in the building. The same trends that were observed for the single passage in figure 8 are also observed in the averaged vibration velocities. The $95 \%$ confidence intervals (CIs) for the vibration velocity levels are displayed as shaded regions on these plots and are of the order of 1-3 dB over the entire frequency range, which is notably narrow when compared to the CIs obtained using train passage measurements at another site [16].

As both the railway track and building are present at this measurement site, the coupling loss values calculated using the vibration velocity levels measured in the free field and the building during train passages represent Case 1 values. Figure 10 shows the average Case 1 coupling loss calculated using equation (6), 


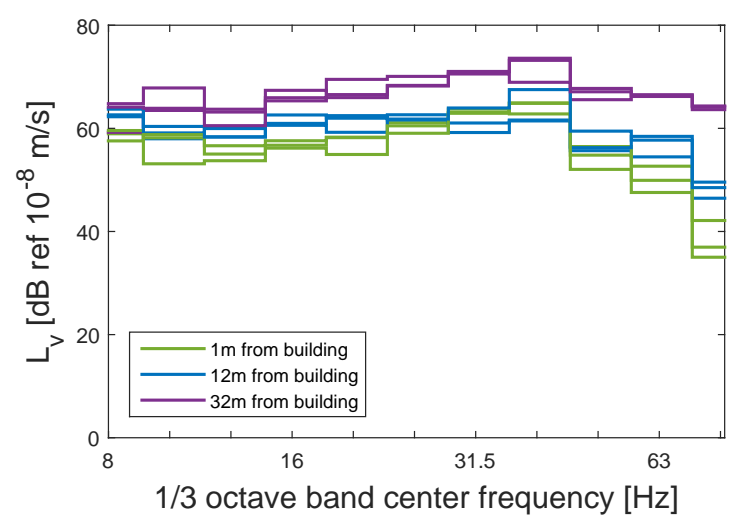

(a)

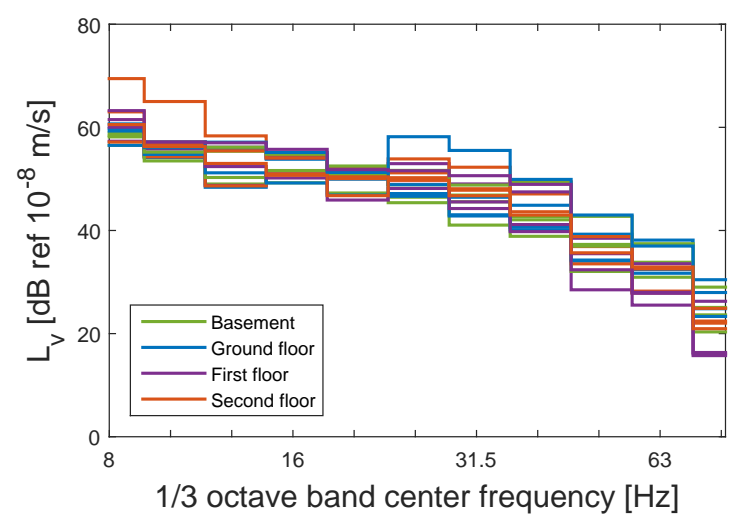

(b)

Figure 8: Vertical vibration velocity levels for a passenger train travelling towards Leuven at $90 \mathrm{~km} / \mathrm{h}$ measured (a) in the free field along three measurement lines; and (b) in Blok D at four measurement locations within each storey.

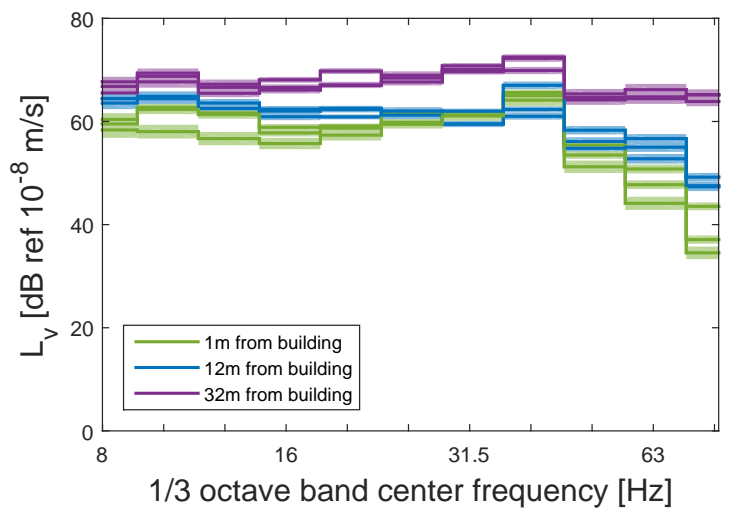

(a)

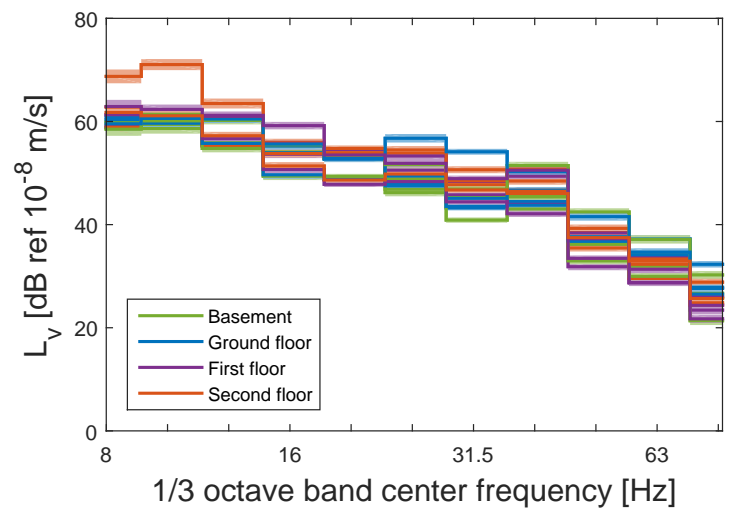

(b)

Figure 9: Average vertical vibration velocity levels determined using 117 passenger train passages (77-100 km/h) measured (a) in the free field along three measurement lines; and (b) in Blok D at four measurement locations within each storey. Shaded areas indicate the $95 \%$ confidence intervals. 
where $\mathbf{x}_{\mathrm{b}}$ is located at each of the four points within the floor space, denoted as sensor locations XX-125-z, XX-113-z, XX-101-z, and XX-309-z, where XX refers to any of the four floor levels. The location of $\mathbf{x}_{1}$ is $1 \mathrm{~m}$ from the building along each of the three measurement lines A, B and C. The $95 \%$ confidence intervals are shown as shaded regions on these plots and are remarkably narrow across the entire frequency range.

Figures 10(a)-(c) show the coupling loss values for building receivers that are located near structural columns, and below the frequency of approximately $25 \mathrm{~Hz}$ there is very little difference between the coupling loss values at various floors for two of these receivers. For sensor position XX-125-z, the trend of increasing floor vibration with increasing floor elevation is observed. Figure 10(d) shows the coupling loss value for a building receiver that is located mid-span, and it can be seen that at less than $11 \mathrm{~Hz}$ there is a large response on the second floor, and, to a lesser extent, on the first floor. Further vibration measurements inside the building and finite element analysis confirmed that this is due to a dominant, fundamental building mode that involves some coupling between the first and second floors. Although it would generally be expected that the mid-span location would have higher vibration levels than the near-column locations, this study shows that this is not always the case.

The greatest variation between the coupling loss values at various floors occurs at frequencies greater than $25 \mathrm{~Hz}$. Comparing the columns in figure 10 (i.e. from top to bottom) gives an indication of how the coupling loss varies with sensor location within building, and comparing the plots along a row (i.e. from left to right) indicates how the coupling loss varies with sensor location within the free field. In general, there is greater similarity along the rows than the columns, which indicates that the coupling loss is more sensitive to the location of the sensor in the building than the location of the sensor in the free field. The main diagonal of figures 10(a) to (c) shows the coupling loss values calculated using the free field sensor that is located closest to the respective building sensors. Due to the symmetry of the measurement setup about the centre of the building, there is the same distance separating sensors XX-125-z/FF-A3-z and sensors XX-101-z/FF$\mathrm{C} 3-\mathrm{z}$ and the coupling loss values at the ground floor bear a strong resemblance. There is a smaller distance separating sensors XX-113-z/FF-B3-z. The level of variation between the four sensor locations within each floor, and between the three free field locations, can be $10 \mathrm{~dB}$ or higher, which represents a significant level of coupling loss dependence on locations $\mathbf{x}_{\mathrm{b}}$ and $\mathbf{x}_{1}$.

It is recognised that the large number of train passages used in this study and the installation of multiple sensors within the building and the free field does not constitute a practical approach for vibration consultants to emulate. We would instead propose the following practical implementation for determining a building's coupling loss: a single sensor within the building, at what could be expected to be a 'higher vibration' location, such as mid-span on the top floor; a single sensor in the free field; an average coupling loss determined using a minimum of fifteen train passages; and a $\pm 10 \mathrm{~dB}$ uncertainty prescribed to the final calculated coupling loss. To illustrate the suitability of this approach, figure 11 shows fifty realisations of the coupling loss, each calculated using the average of fifteen randomly sampled train passages from the 


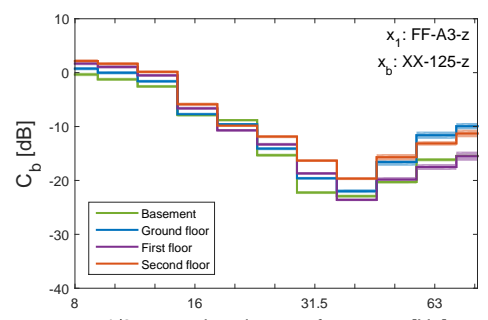

(a)

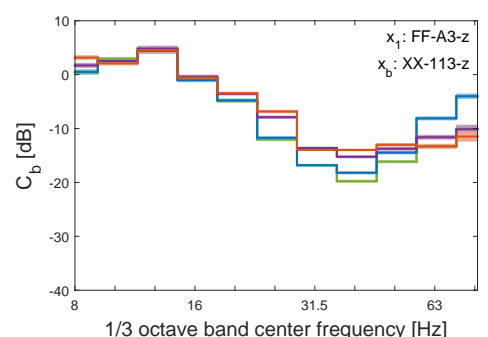

(b)

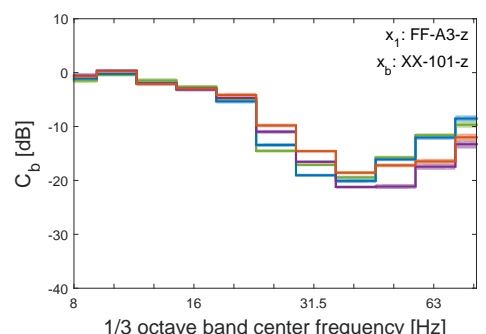

(c)
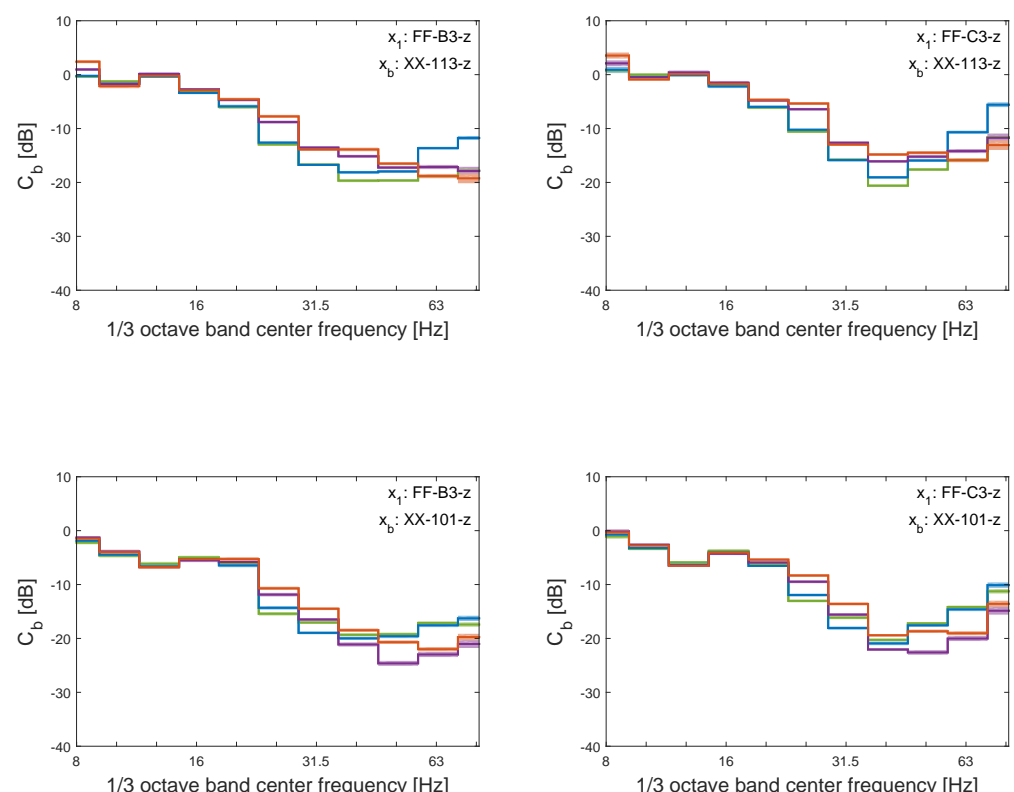

$1 / 3$ octave band center frequency $[\mathrm{Hz}]$

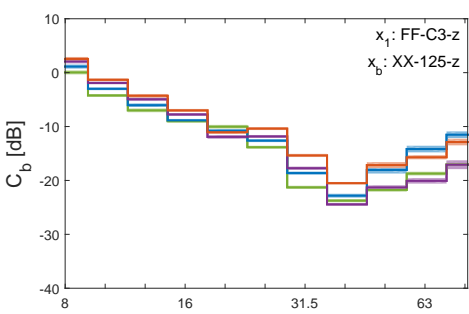

$1 / 3$ octave band center frequency $[\mathrm{Hz}]$

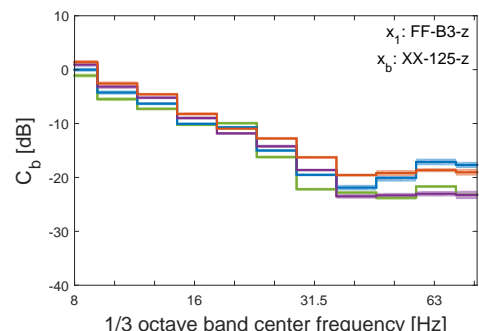

3 octave band center frequency $[\mathrm{Hz}]$

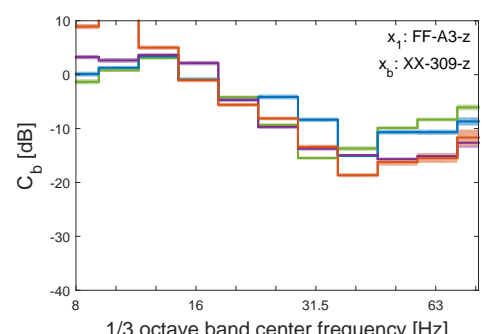

(d)
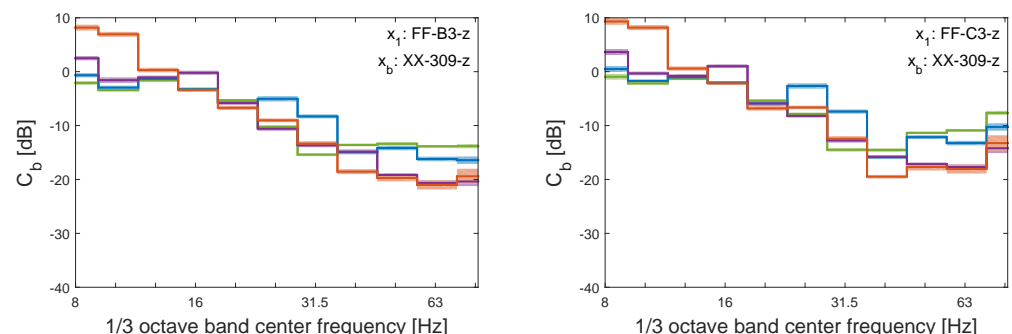

Figure 10: Average Case 1 coupling loss values calculated with receiver points $\mathbf{x}_{\mathrm{b}}$ at various floors with locations (a) XX-125-z; (b) XX-113-z; (c) XX-101-z; and (d) XX-309-z, determined using the passage of 117 passenger train passages (77-100 km/h). Free field receiver points $\mathbf{x}_{1}$ are located $1 \mathrm{~m}$ from the building on measurement lines A, B and C (left to right). Shaded areas indicate the $95 \%$ confidence intervals. 
total set of 117 passages. For comparison, the average of the total passage set is also shown, and for all of the realisations the coupling loss is within $10 \mathrm{~dB}$ of the total set average.

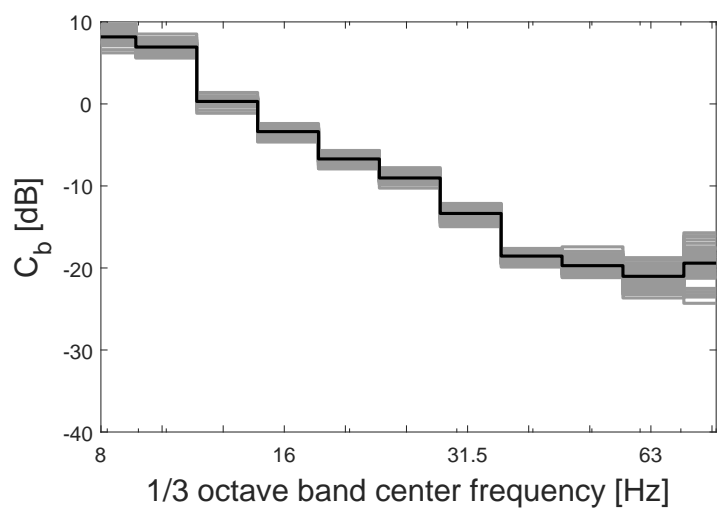

Figure 11: The average coupling loss determined using the total set of 117 train passages with receiver points $\mathbf{x}_{\mathrm{b}}$ at mid-span on the top floor (02-309-z) and free field receiver point $\mathbf{x}_{1}$ is located $1 \mathrm{~m}$ from the building on measurement line B (in black). Shown in grey are fifty realisations of the average coupling losses determined using fifteen randomly sampled passenger train passages from the total set of 117 passages.

\subsubsection{Coupling loss using hammer impacts}

Figure 12 shows point source transfer mobilities in the free field and in the building using over 100 hammer impacts on the sleeper located at $y=0$. Non-uniform decay with increasing distance from the track is again seen in the free field. As the attenuation is stronger for higher frequencies, the peak of the frequency content is shifted towards lower frequencies. There appears to be some trend of vibration amplification with floor height in the frequency range of 8-32 Hz.

Figure 13 shows the line source transfer mobilities in the free field and in the building, determined as the summation of the seventeen point source transfer mobilities according to equation (5). Apart from the increase in magnitude due to the summation of multiple point source transfer mobilities, the line source transfer mobilities bear a strong similarity to the point source transfer mobilities shown in figure 12 .

To examine the assumption of equivalent force densities, figure 14 shows the force density terms calculated using the average vibration velocities shown in figure 9 and the line source transfer mobilities shown in figure 13. It can be seen from these plots that the magnitude and the frequency dependence of the force density is similar regardless of which receiver points are used. There exists some scatter, particularly at frequencies greater than $35 \mathrm{~Hz}$, but this scatter does not show a strong dependance on distance from the building nor floor elevation. The assumption of equivalent force terms therefore appears to be reasonable for this site.

The approximate Case 1 coupling loss values can be calculated as per equation (10) using the line source 


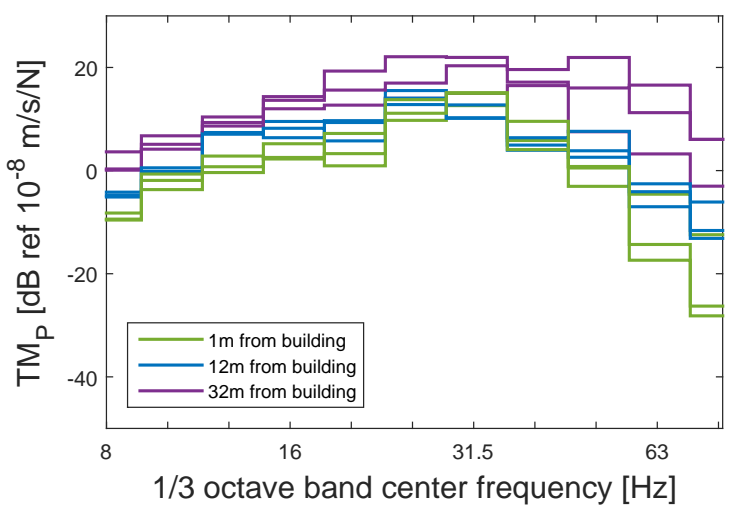

(a)

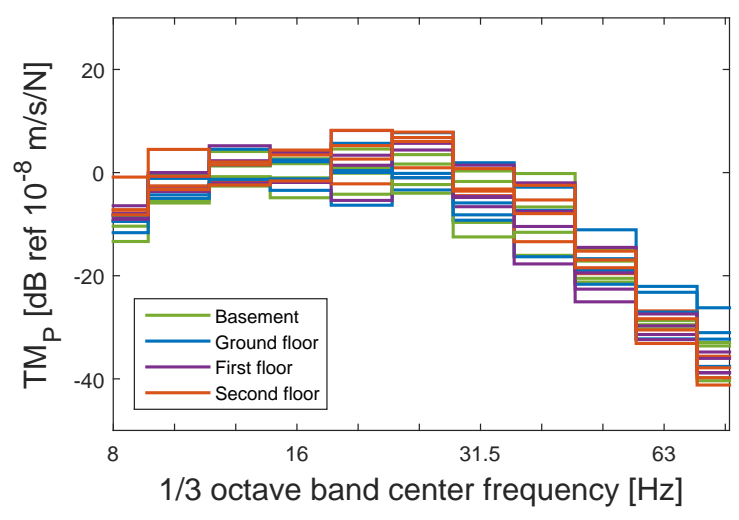

(b)

Figure 12: Point source transfer mobilities determined using more than 100 hammer excitations on the sleeper at $y=0$ and measured (a) in the free field along three measurement lines; and (b) in Blok D at four measurement locations within each storey.

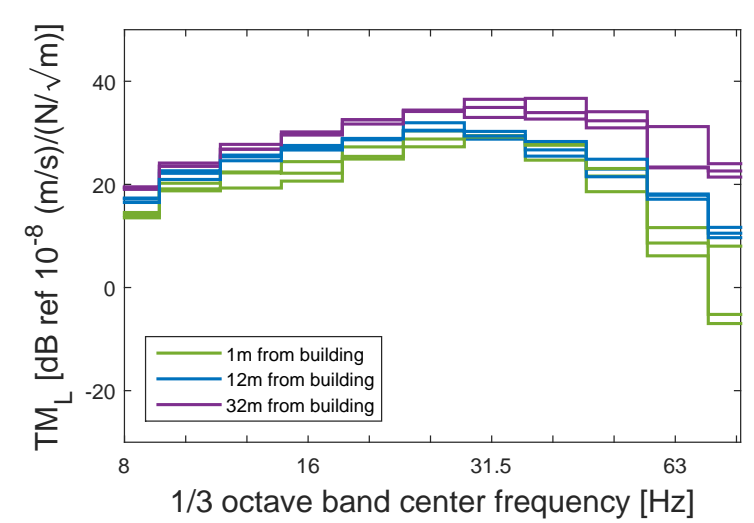

(a)

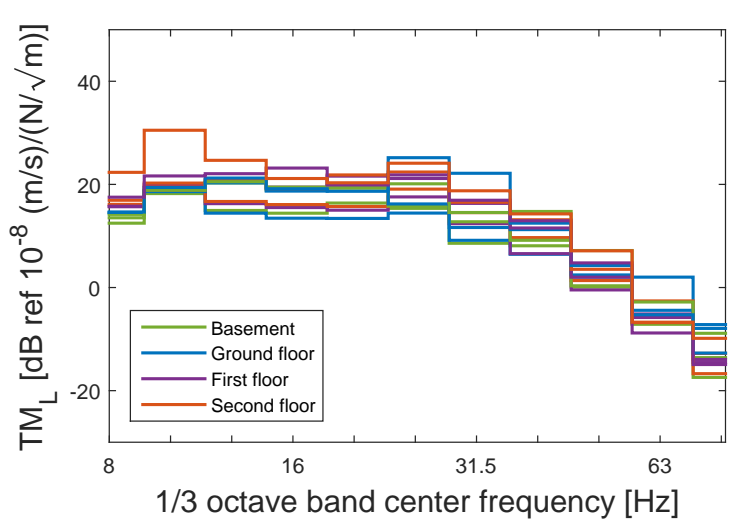

(b)

Figure 13: Line source transfer mobilities determined using more than 100 hammer excitations on the sleeper at each of seventeen source locations and measured (a) in the free field along three measurement lines; and (b) in Blok D at four measurement locations within each storey. 


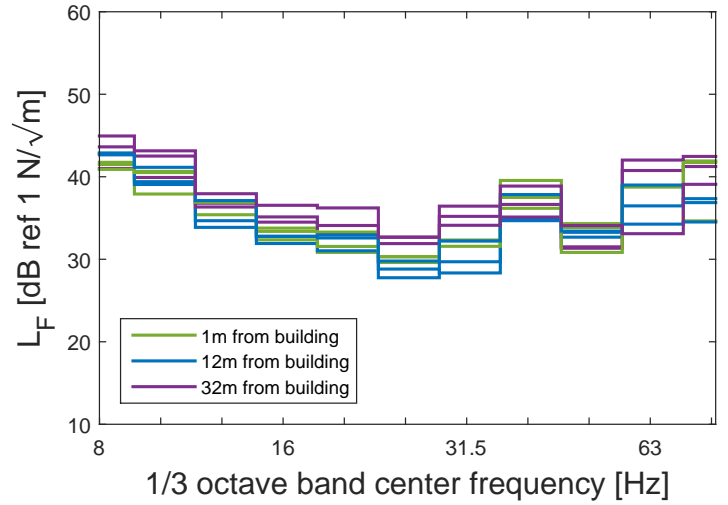

(a)

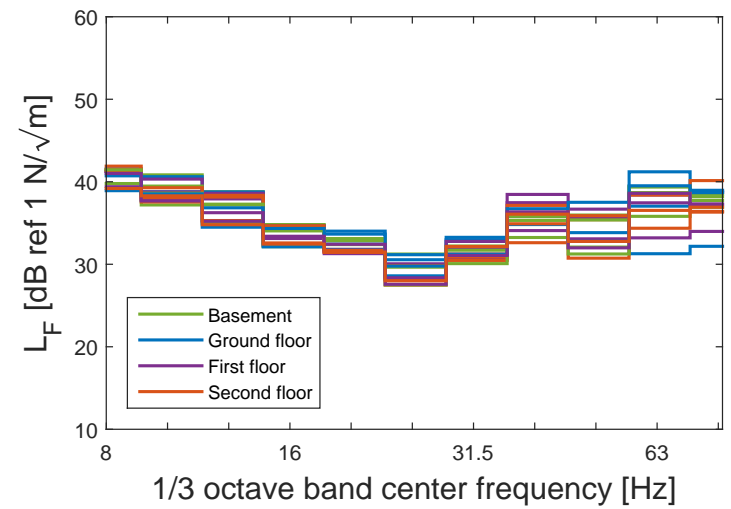

(b)

Figure 14: Force density calculated using average vibration velocities resulting from 117 passenger train passages (77-100 km/h) and line source transfer mobilities determined using more than 100 hammer excitations on the sleeper at each of seventeen source locations. Sensors are located (a) in the free field along three measurement lines; and (b) in Blok D at four measurement locations within each storey.

transfer mobilities obtained from the hammer impact measurements, and are shown in figure 15] As is expected having demonstrated the equivalence of force density terms, these approximate Case 1 coupling loss values show a strong likeness to the Case 1 coupling loss values shown in figure 10, both in terms of magnitude and variation with frequency. There is especially good agreement at frequencies below $25 \mathrm{~Hz}$ for all sensor locations. The greatest deviations occur at above $35 \mathrm{~Hz}$, where the approximate Case 1 coupling loss values generally show greater scatter in the floor-to-floor attenuation. The magnitude of these deviations lie within the proposed uncertainty window of $\pm 10 \mathrm{~dB}$ for the Case 1 coupling loss values, thus it can be concluded that the introduction of the line source transfer mobility approximation does not represent a significant increase in uncertainty level for characterisation of the building's coupling loss.

The closeness of the approximate Case 1 coupling loss values to the coupling losses calculated using train passages has important practical implications. Firstly, it demonstrates that a building's coupling loss can be estimated with reasonable accuracy without the existence of train passages, which means in the case of a new railway the track does not yet have to be operational. Secondly, this shows that using hammer impacts, which produce a much smaller magnitude of ground-borne vibration than train passages, nevertheless enables the coupling loss to be quantified with reasonable accuracy. Thirdly, although more than one hundred hammer impacts were applied at each source location for this study, it has previously been shown that using twenty impacts is sufficient for determining the point source transfer mobilities [16]. Furthermore, it has also been shown that using a source length of $200 \mathrm{~m}$ with source point spacing of $10 \mathrm{~m}$ (similar to what was done in this study) does not produce a significantly different line source transfer mobility to a source length of $100 \mathrm{~m}$ with a source point spacing of $20 \mathrm{~m}$ [13]. For these reasons, we propose 
the following practical implementation for determining the building's coupling loss as an alternative to that in section 4.2.1 a single sensor within the building, at what would be expected to be a higher vibration location, such as mid-span on the top floor; a single sensor in the free field; a coupling loss determined using a line source transfer mobility with a source length of $100 \mathrm{~m}$, source point spacing of $20 \mathrm{~m}$, and a minimum of 20 impacts at each source point; and $\mathrm{a} \pm 10 \mathrm{~dB}$ uncertainty prescribed to the final calculated coupling loss.

To investigate the appropriateness of this practical implementation, figure 16 compares the approximate coupling loss value calculated using line source transfer mobilities determined with seventeen sources $(n=17)$ with spacing $h=12 \mathrm{~m}$ and total length of $192 \mathrm{~m}$ to that calculated using a reduced number of sources, namely nine sources with spacing $h=12 \mathrm{~m}$, giving a total length of $96 \mathrm{~m}$, and five sources $(n=5)$ with spacing $h=24 \mathrm{~m}$, also with total length $96 \mathrm{~m}$. Also illustrated in this figure using dotted lines is the effect of using only twenty impacts at every source position. The variation due to the reduced number of sources and hammer impacts is less than $5 \mathrm{~dB}$ over the entire frequency range, which illustrates that this practical implementation provides a suitably accurate means of determining the coupling loss at these sensor locations.

\section{Coupling loss evaluation using modelling}

\subsection{Introduction}

A 2.5D coupled FE-BE model has been used to evaluate the coupling loss values using different configurations of the railway-soil-building in [17, 18]. These configurations include (a) the railway and a nearby building; (b) the railway and the surrounding soil; and (c) a building excited by nearby impulses on the soil's surface. This model is decoupled in that the dynamic vehicle or surface loads are calculated first and then applied to the track, foundation or ground surface for calculation of the free field and building response. Although this approach does not produce a realistic building geometry, and therefore the validity of the resulting coupling loss values are limited, it does provide a means of assessing the effect of the assumption of separate source, propagation and receiver terms. It is shown that the presence of the building attenuates free field vibrations, and there exists good agreement between all three cases provided that the surface measurement point is a small distance from the building foundation. Using approximate expressions that remove the requirement of a train passage, thus assuming decoupling of the source term, do not result in a loss of modelling accuracy.

The influence of structural parameters and dynamic soil characteristics on the building's coupling loss values is investigated in this section using a $3 \mathrm{D}$ model of a realistic, representative building. Based on the findings of the measurement study in section 4 and the 2.5D modelling results, the source term is assumed decoupled in this modelling study. The railway is represented as a series of seven equidistant on- 


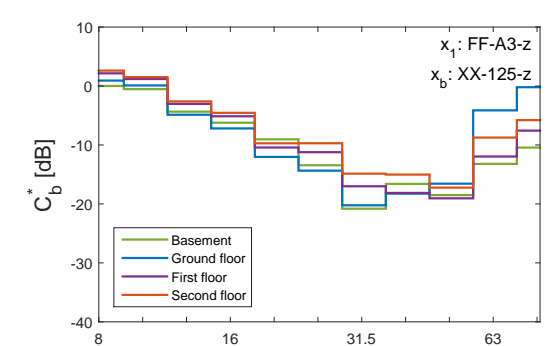

(a)

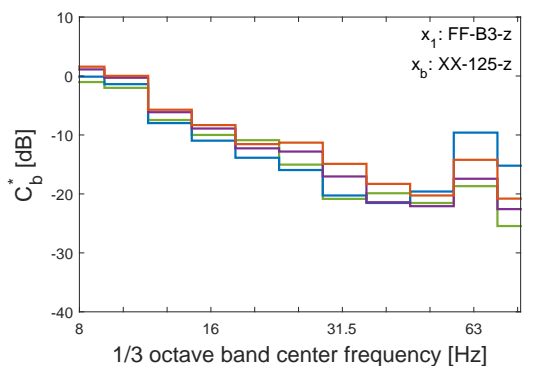

$1 / 3$ octave band center frequency $[\mathrm{Hz}]$
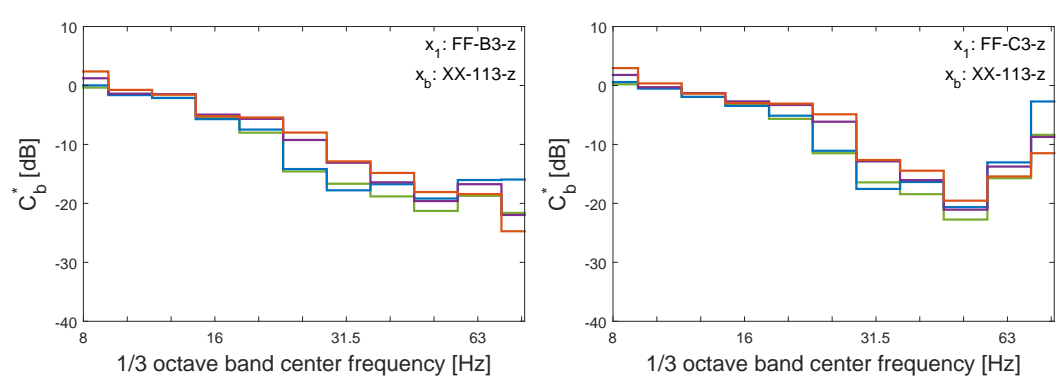

(b)
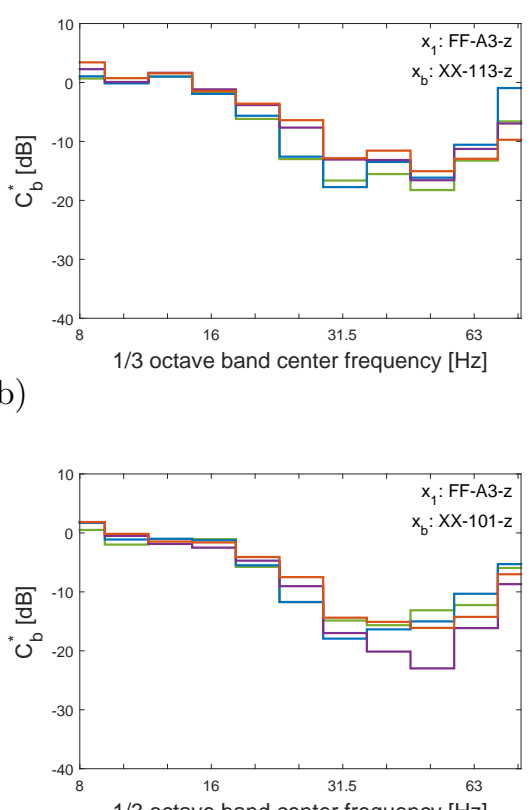

(c)

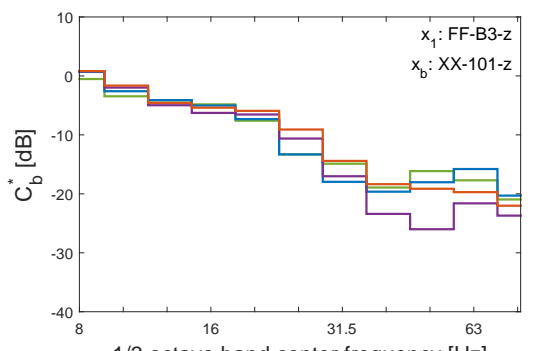

$\begin{array}{ccc}16 & 31.5 & 63 \\ 1 / 3 & \text { octave band center frequency }[\mathrm{Hz}]\end{array}$

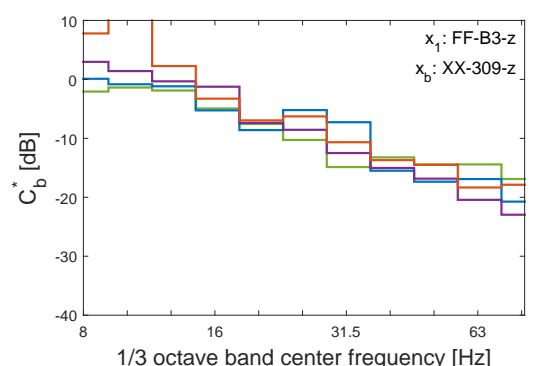

$1 / 3$ octave band center frequency [ $\mathrm{Hz}]$

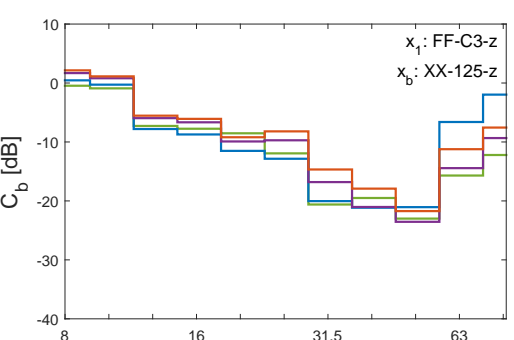

$1 / 3$ octave band center frequency $[\mathrm{Hz}]$
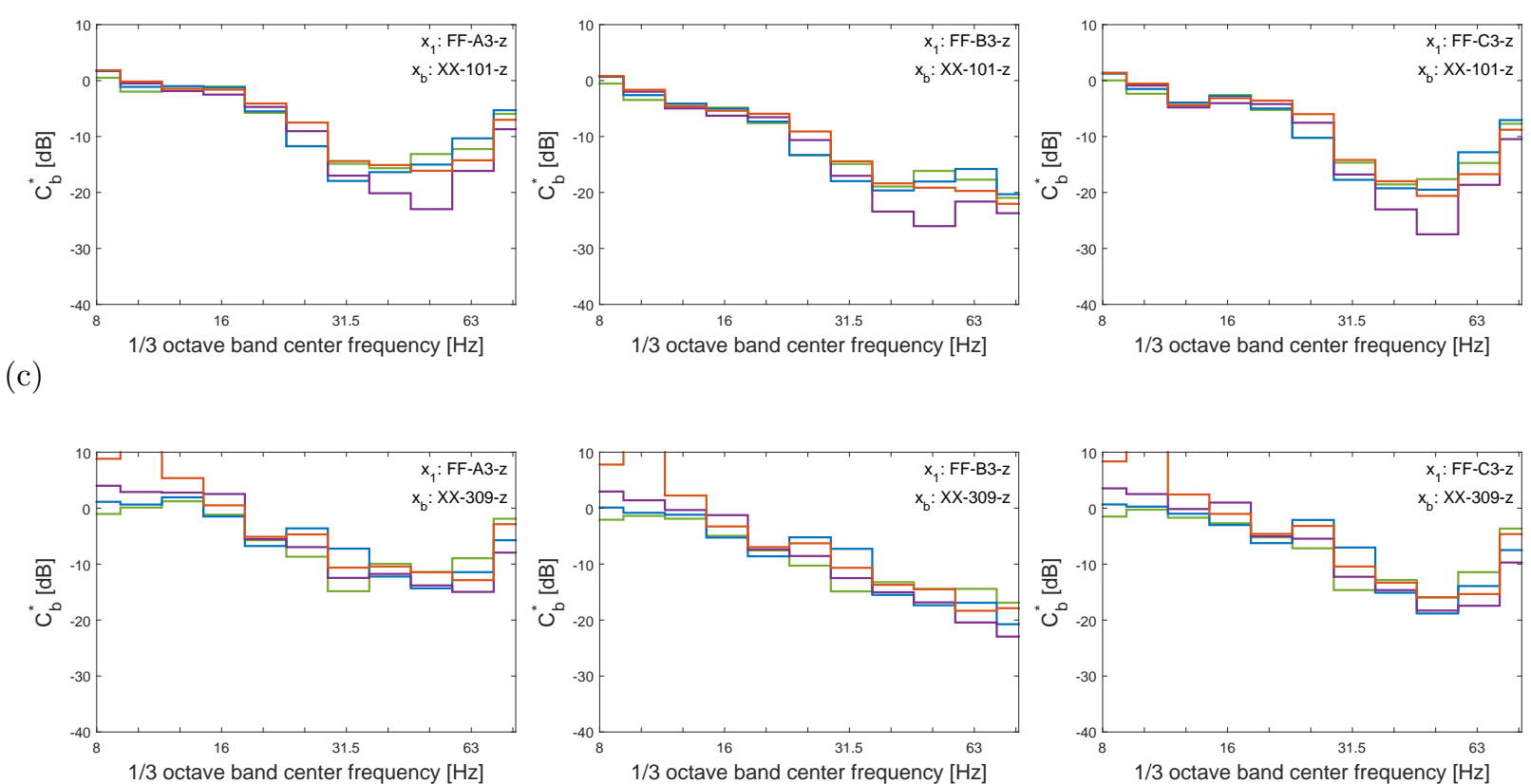

$1 / 3$ octave band center frequency $[\mathrm{Hz}]$

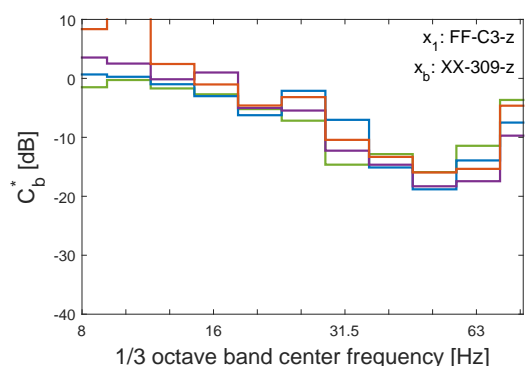

(d)

Figure 15: Approximate Case 1 coupling loss values calculated with receiver points $\mathbf{x}_{\mathrm{b}}$ at various floors with locations (a) XX-125-z; (b) XX-113-z; (c) XX-101-z; and (d) XX-309-z, determined using hammer impacts on the track. Free field receiver points $\mathbf{x}_{1}$ are located $1 \mathrm{~m}$ from the building on measurement lines $\mathrm{A}, \mathrm{B}$ and $\mathrm{C}$ (left to right). 


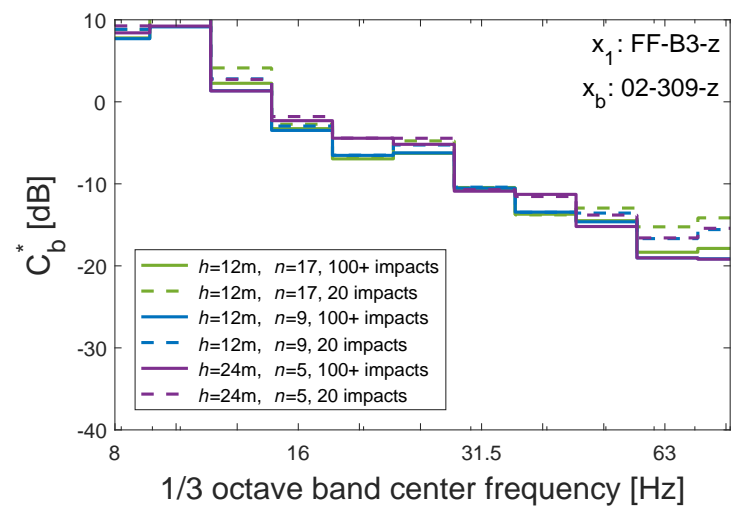

Figure 16: Approximate Case 1 coupling loss values calculated with receiver point $\mathbf{x}_{\mathrm{b}}$ at mid-span on the top floor (02-309-z) and free field receiver point $\mathbf{x}_{1}$ is located $1 \mathrm{~m}$ from the building on measurement line B, using various source configurations and numbers of hammer impacts for determining the line source transfer mobilities.

soil impacts, spaced at $20 \mathrm{~m}$. This represents Case 3 coupling loss, and the relevant coupling loss expression is equation (14).

\subsection{Methodology}

Computationally, the problem is split into the source subproblem and the receiver subproblem, assuming that the two subproblems are weakly coupled [2]. In the source subproblem, shown in figure 17a, transfer functions caused by the fixed, incoherent and equal point loads are computed using the direct stiffness method for elastodynamics [19, 20] relating the applied point loads to the displacements of the free field at the location of the receiver. This enables the line source transfer mobility to be computed using equation (5). The distance of the point loads from the building is $h=30 \mathrm{~m}$, and the receivers $\mathbf{x}_{1}$ are located at $1 \mathrm{~m}, 2 \mathrm{~m}$ and $3 \mathrm{~m}$ from the building. The receiver subproblem, shown in figure $17 \mathrm{~b}$, corresponds to the building being excited by the incident wave field that has been computed using the source model. It is solved separately using a coupled FE-BE model.

The reference structure is a six-story reinforced concrete building. The height of each story is $3 \mathrm{~m}$ and the total height of the building is $18 \mathrm{~m}$. Figure 18 shows the plan view of a typical floor. The cross section of the external columns $(\mathrm{C} 1)$ is rectangular with dimensions $0.3 \mathrm{~m} \times 0.7 \mathrm{~m}$ whereas the cross section of the internal columns (C2) is square with dimensions $0.5 \mathrm{~m} \times 0.5 \mathrm{~m}$. The beams $(\mathrm{B})$ have rectangular cross sections with dimensions $0.25 \mathrm{~m} \times 0.5 \mathrm{~m}$. The thickness of the walls and the shaft are respectively $0.30 \mathrm{~m}$ and $0.25 \mathrm{~m}$. The slabs have a thickness of $0.18 \mathrm{~m}$. The columns of the building are founded on individual footings, the walls on strip footings and the building's shaft on a raft foundation (figure 19a). The individual footings have dimensions $1.5 \mathrm{~m} \times 1.5 \mathrm{~m}$ and a thickness of $0.8 \mathrm{~m}$. The strip footings have dimensions $1.5 \mathrm{~m} \times 6.24 \mathrm{~m}$ and a thickness of $0.3 \mathrm{~m}$. The raft foundation has a thickness of $1 \mathrm{~m}$. The concrete has Young's modulus 


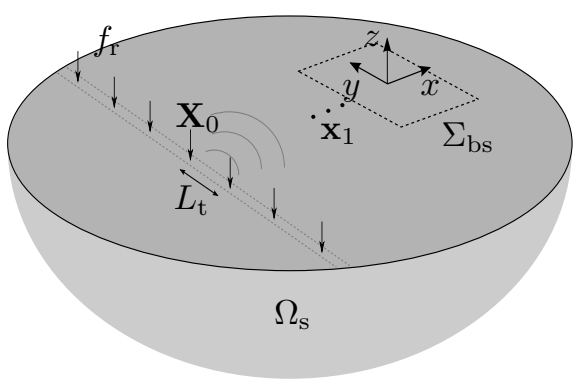

(a)

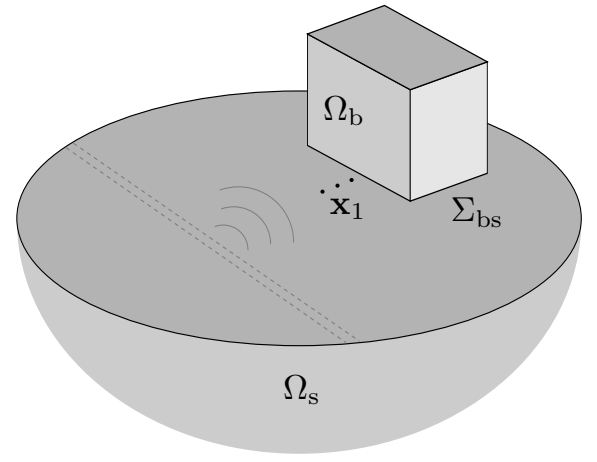

(b)

Figure 17: (a) Source model and (b) receiver model.

$E_{c}=30 \mathrm{GPa}$, Poisson's ratio $\nu_{c}=0.3$ and density $\rho_{c}=2500 \mathrm{~kg} / \mathrm{m}^{3}$. Hysteretic damping is assumed with hysteretic damping ratio $\eta=0.03$. The floors of the building have an extra mass of $250 \mathrm{~kg} / \mathrm{m}^{2}$. The soil is modeled as a homogeneous halfspace with shear wave velocity $C_{\mathrm{s}}=200 \mathrm{~m} / \mathrm{s}$, longitudinal wave velocity $C_{\mathrm{p}}=400 \mathrm{~m} / \mathrm{s}$, density $\rho=1800 \mathrm{~kg} / \mathrm{m}^{3}$ and hysteretic damping ratio $\beta=0.03$.

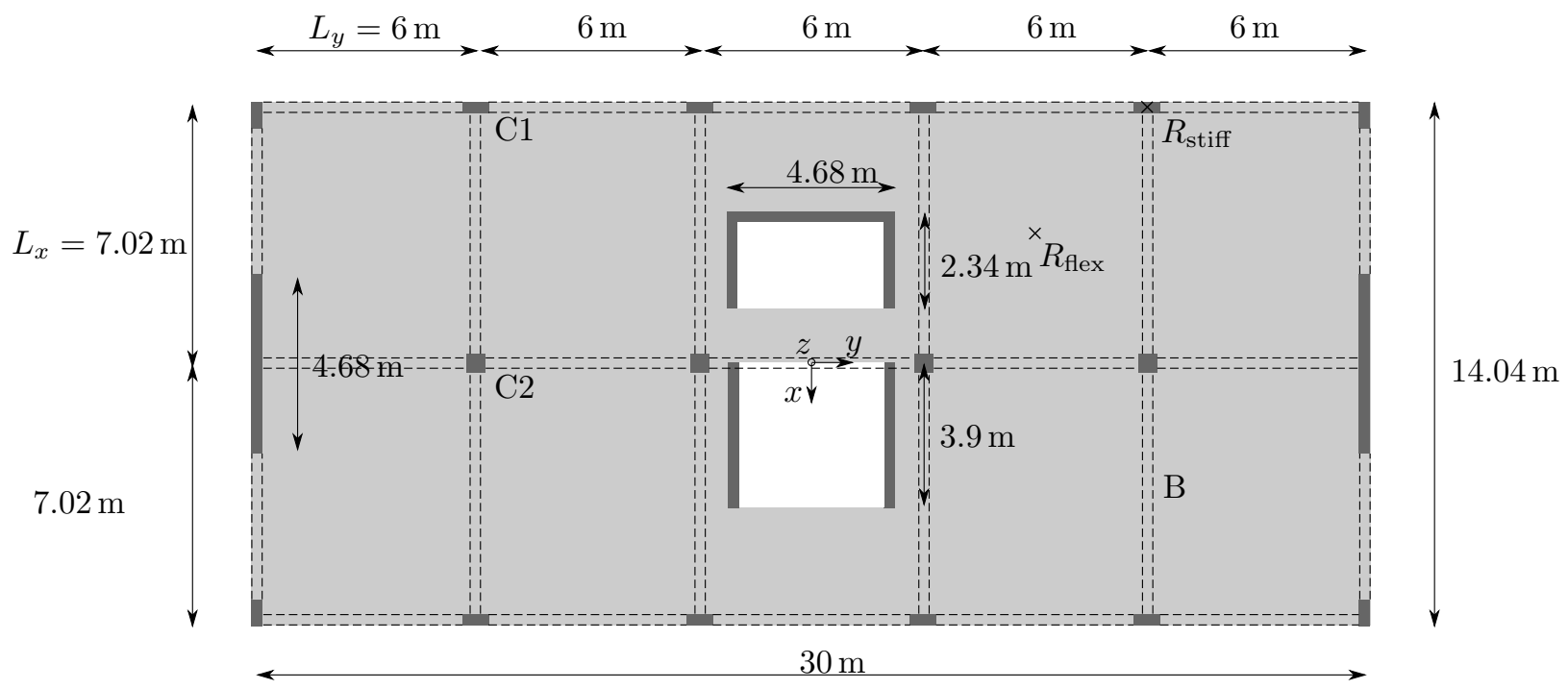

Figure 18: Plan view and dimensions of a typical floor of the building. B denotes the beams while C1 and C2 indicate the columns. The receiver locations $R_{\text {stiff }}$ and $R_{\text {flex }}$ correspond to a stiff and a flexible location of the building, respectively.

Alternative structural configurations are examined by considering different: (a) slab thickness, (b) layout dimensions and (c) number of stories. Table 1 summarizes the characteristics of the additional structural configurations. As shown in table 1, the cross section of the beams and the slabs is adjusted appropriately for each of the considered layout dimensions.

In order to investigate the influence of the dynamic soil characteristics on the coupling loss, three soil cases 


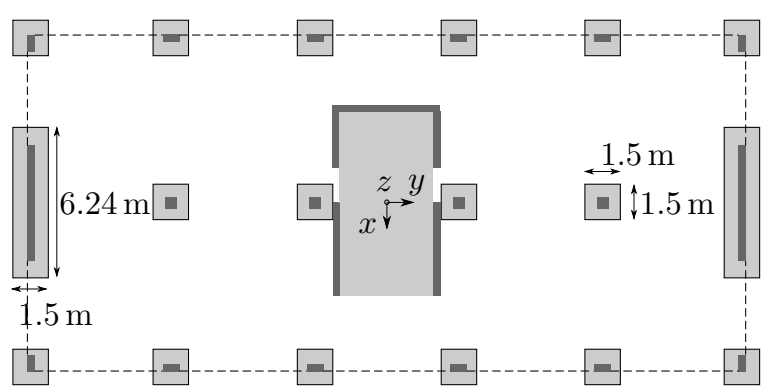

(a)

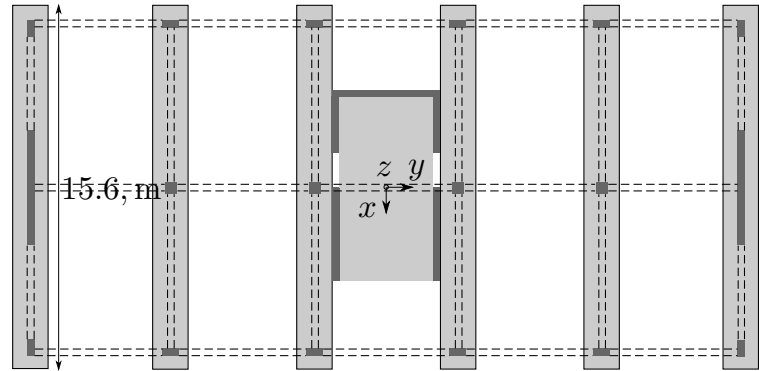

(b)

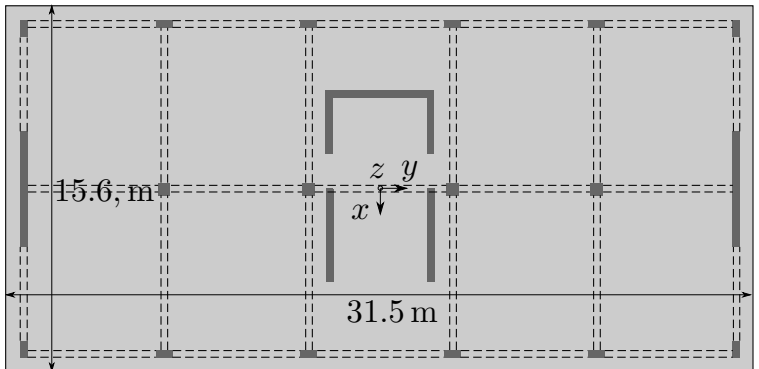

(c)

Figure 19: Foundation types: (a) Individual footings, (b) strip foundation and (c) raft foundation.

\begin{tabular}{llccccc}
\hline & Building Property & Parameter & Units & \multicolumn{3}{c}{ Cases } \\
\hline a & Slab thickness & $t_{\mathrm{s}}$ & {$[\mathrm{m}]$} & 0.17 & 0.19 & 0.215 \\
\hline \multirow{2}{*}{$\mathrm{b}$} & \multirow{2}{*}{ Layout dimensions } & $L_{x}$ & {$[\mathrm{~m}]$} & 5.46 & 7.02 & 8.58 \\
& & $L_{y}$ & {$[\mathrm{~m}]$} & 4.50 & 6 & 7.50 \\
\hline \multirow{2}{*}{ c } & Beam cross-section & $\mathrm{B}$ & {$[\mathrm{m} \times \mathrm{m}]$} & $0.40 \times 0.25$ & $0.50 \times 0.25$ & $0.60 \times 0.30$ \\
\hline d & Number of stories & $n_{\mathrm{st}}$ & {$[-]$} & 4 & 6 & 8 \\
\hline
\end{tabular}

Table 1: Examined structural configurations.

are considered for the reference building. The corresponding surface foundation types have been modified according to the soil conditions. Table 2 shows the three soil types that have been considered, where soil 2 corresponds to the reference case. For soil 1, a softer soil, a strip and a raft foundation are examined. For soil 3, a stiffer soil, a strip foundation and the original foundation configuration are examined. All three foundation types are examined for soil 2 .

Figure 20 shows the FE-BE model of the reference building for the three different surface foundation types. The walls, floors, footings and strip foundations are modelled with eight-node shell elements and the beams and columns are modelled with two-node beam elements. The boundary element mesh conforms to 


\begin{tabular}{ccccc}
\hline & $\begin{array}{c}C_{\mathrm{s}} \\
{[\mathrm{m} / \mathrm{s}]}\end{array}$ & $\begin{array}{c}C_{\mathrm{p}} \\
{[\mathrm{m} / \mathrm{s}]}\end{array}$ & $\begin{array}{c}\rho \\
{\left[\mathrm{kg} / \mathrm{m}^{3}\right]}\end{array}$ & $\begin{array}{c}{[-]} \\
{[-]}\end{array}$ \\
\hline Soil 1 & 100 & 200 & 1800 & 0.03 \\
Soil 2 & 200 & 400 & 1800 & 0.03 \\
Soil 3 & 300 & 600 & 1800 & 0.03 \\
\hline
\end{tabular}

Table 2: Dynamic soil properties.

the finite element mesh at the soil-foundation interface $\Sigma_{\mathrm{bs}}$ in order to facilitate finite element-boundary element coupling. A maximum finite/boundary element size $l_{e}=0.78 \mathrm{~m}$ is chosen such that the model is accurate up to $80 \mathrm{~Hz}$. The FE-BE system of equations is:

$$
\mathbf{S}(\omega) \underline{\hat{\mathbf{u}}}=\left[\mathbf{K}_{\mathrm{b}}(1+\mathrm{i} \eta)-\omega^{2} \mathbf{M}_{\mathrm{b}}+\mathbf{K}_{\mathrm{s}}(\omega)\right] \underline{\hat{\mathbf{u}}}=\underline{\hat{\mathbf{f}}}_{\mathrm{b}}+\underline{\hat{\mathbf{f}}}_{\mathrm{s}}
$$

where $\mathbf{K}_{\mathrm{b}} \in \mathbb{R}^{n \times n}$ and $\mathbf{M}_{\mathrm{b}} \in \mathbb{R}^{n \times n}$ are the stiffness and mass matrix of the building with $n$ the number of degrees of freedom in the model, $\mathbf{K}_{\mathrm{s}}(\omega) \in \mathbb{C}^{n \times n}$ is the dynamic stiffness of the soil, $\underline{\hat{\mathbf{u}}} \in \mathbb{C}^{n}$ is a vector collecting the nodal displacements, $\underline{\hat{f}}_{\mathrm{b}} \in \mathbb{C}^{n}$ is a vector collecting the external forces on the building and $\hat{\mathbf{f}}_{\mathrm{s}} \in \mathbb{C}^{n}$ is a vector collecting the equivalent nodal forces due to the excitation of the building by the incident wave field.

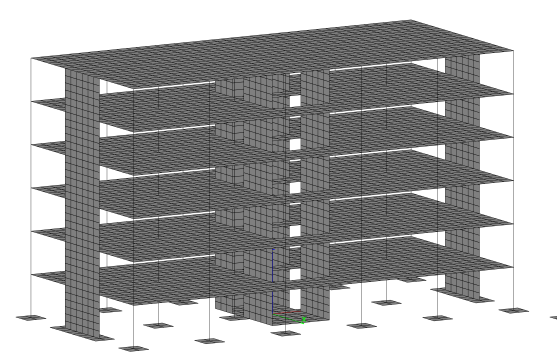

(a)

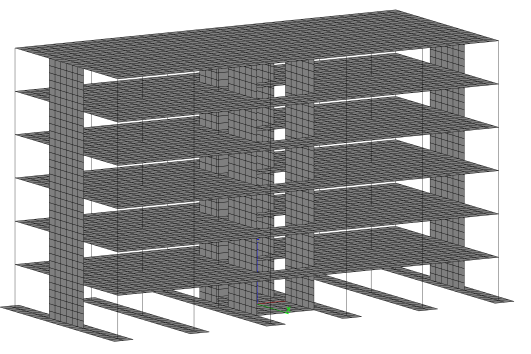

(b)

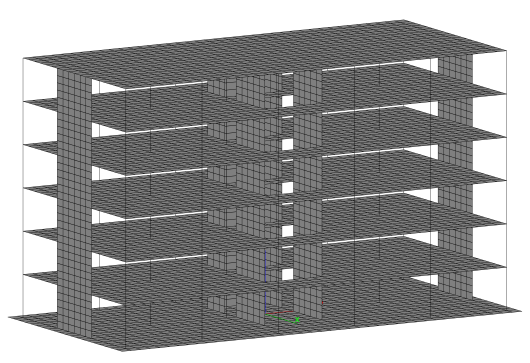

(c)

Figure 20: FE-BE models of the building. Building with (a) Footings, (b) Strip foundations and (c) raft foundation.

The modal characteristics of the building, neglecting structural damping, can be computed by solving the non-linear eigenvalue problem:

$$
\mathbf{S}\left(\omega_{j}\right) \boldsymbol{\psi}_{j}=\left[\mathbf{K}_{\mathrm{b}}-\omega_{j}^{2} \mathbf{M}_{\mathrm{b}}+\mathbf{K}_{\mathrm{s}}\left(\omega_{j}\right)\right] \boldsymbol{\psi}_{j}=\mathbf{0}
$$

where $\omega_{j} \in \mathbb{R}$ and $\boldsymbol{\psi}_{j} \in \mathbb{C}^{n}(j=1, \ldots, n)$ are the $j$-th eigenfrequency and eigenvector of the coupled soilstructure system. The solution of this non-linear eigenvalue problem is computationally demanding. It is simplified here by assuming that the dynamic stiffness $\mathbf{K}_{\mathrm{s}}(\omega)$ is independent of $\omega$ such that $\mathbf{K}_{\mathrm{s}}(\omega) \approx$ $\mathbf{K}_{\mathrm{s}}(0) \in \mathbb{R}^{n \times n}$ where $\mathbf{K}_{\mathrm{s}}(0)$ is the static stiffness of the soil. This assumption results in the generalized 
eigenvalue problem:

$$
\mathbf{S}\left(\omega_{j}\right) \boldsymbol{\varphi}_{j}=\left[\mathbf{K}_{\mathrm{b}}-\omega_{j}^{2} \mathbf{M}_{\mathrm{b}}+\mathbf{K}_{\mathrm{s}}(0)\right] \boldsymbol{\varphi}_{j}=\mathbf{0}
$$

where $\varphi_{j} \in \mathbb{R}^{n}(j=1, \ldots, n)$ is the $j$-th eigenvector of the coupled soil-structure system.

Figure 21 shows the modal density of the reference building for the three different foundation types. At low frequencies, below approximately $20 \mathrm{~Hz}$, the modes are well separated whereas at higher frequencies the modes are increasingly closely spaced. Six mode shapes of the reference building are shown in figure 22 , The first three modes are global modes of the building - two lateral and one torsional, whilst the higher order modes are predominantly vertical modes of the floors. Similar modes are also obtained for the other structural configurations and foundation types, but at slightly different eigenfrequencies.

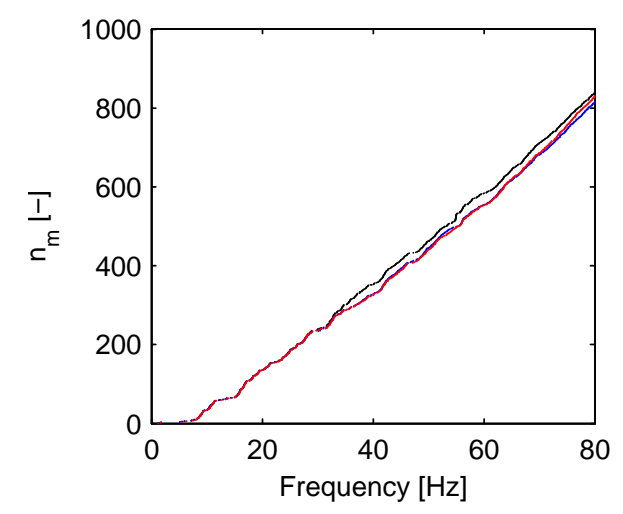

Figure 21: Modal density of the building with footings (black), strip foundations (blue) and raft foundation (red).

\subsection{Parametric study}

\subsubsection{Effect of soil properties and foundation type}

The effect of soil properties and foundation type on the line source transfer mobilities with receivers on the ground surface at $1 \mathrm{~m}, 2 \mathrm{~m}$ and $3 \mathrm{~m}$ from the building is shown in figure 23. As the foundation type varies for soil 2 , there is little variation in the line source transfer mobilities, as would be expected for these ground-surface receivers. However, the dynamic soil properties have a strong influence on the line source transfer mobilities. An increase in the soil stiffness generally results in a shift in the maximum vibration response to higher frequencies. The effects of dynamic soil-structure interaction can be observed by comparing the results in the presence of the building (solid lines) with the results in the absence of the building (dashed lines). In general, the greatest effect occurs below the $16 \mathrm{~Hz}$ band, with the presence of the building resulting in an increase of $0-3 \mathrm{~dB}$ in the line source transfer mobilities, with the exception of a few localised one-third octave bands. These trends are observed across all three ground surface locations, which indicates that a similar level of dynamic soil structure interaction is experienced at $1 \mathrm{~m}, 2 \mathrm{~m}$ and $3 \mathrm{~m}$ from 

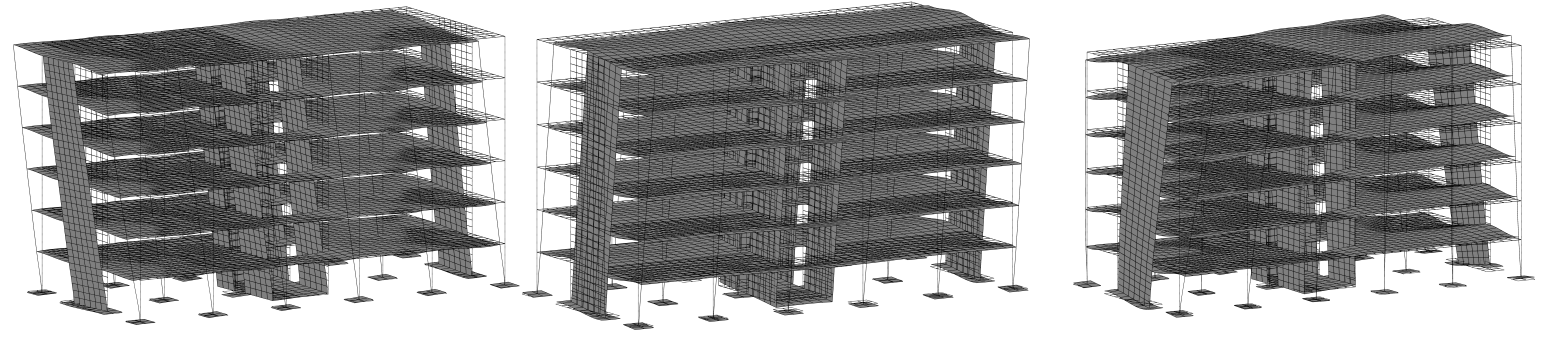

(a)

(b)

(c)

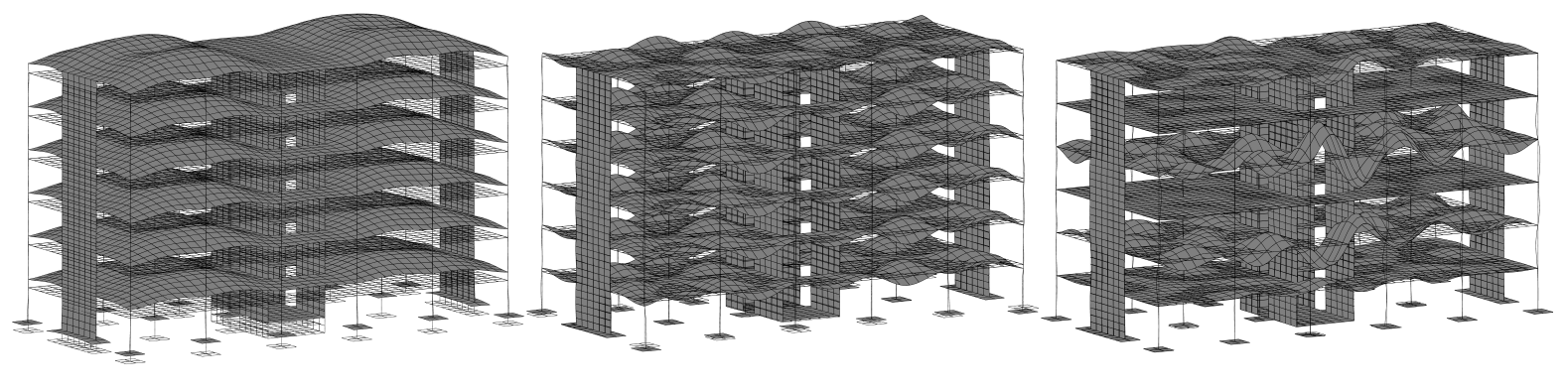

(d)

(e)

(f)

Figure 22: Modes of the reference building model. (a) $1^{\text {st }}$ mode at $1.16 \mathrm{~Hz}$, (b) $2^{\text {nd }}$ mode at $1.55 \mathrm{~Hz}$, (c) $3^{\text {rd }}$ mode at $1.68 \mathrm{~Hz}$, (d) $4^{\text {th }}$ mode at $5.13 \mathrm{~Hz}$, (e) $287^{\text {th }}$ mode at $34.03 \mathrm{~Hz}$, and (f) $353^{\text {th }}$ mode at $40.03 \mathrm{~Hz}$.

this building. From this it can be concluded that the effect of using a line source transfer mobility measured on the ground surface in the absence of a building may introduce an uncertainty of approximately $3 \mathrm{~dB}$ to the coupling loss value.

The building's coupling loss terms are calculated as the difference in the line source transfer mobilities measured with the receiver in the building, and in the free field in the presence of the building. These are shown in figure 24 for the various soil properties and foundation types, with the building receiver located at a stiff location, and the free field receiver located $1 \mathrm{~m}$ from the building. It can be seen that as the foundation type varies for soil 2 , there is little variation in the coupling loss. Both the trend of floor to floor amplification or attenuation (represented by the variance in shading) and the attenuating effects of the foundation on the free field vibration levels, represented by the magnitude of the coupling loss, are not significantly influenced by the foundation type. However, the dynamic soil properties have a strong influence on the building's coupling loss for both the reference foundation and the raft foundation. An increase in the soil stiffness generally results in a shift in the vibration response to higher frequencies. This trend is present in the both the free field line source transfer mobility and the line source transfer mobility with receivers in the building. The coupling loss shows a strong dependence on frequency, with variations of the order of at least $10 \mathrm{~dB}$ over the frequency range of interest.

The mid-span amplification within the building has been calculated as the difference between the line 
Reference foundation

Soil 1

Soil 2

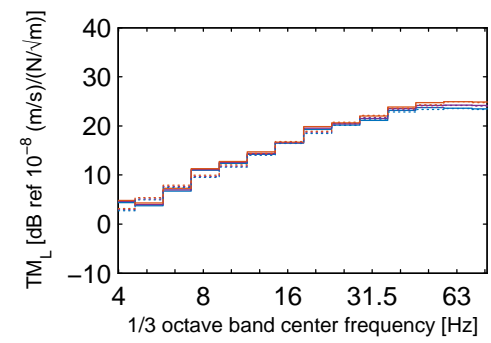

(c)

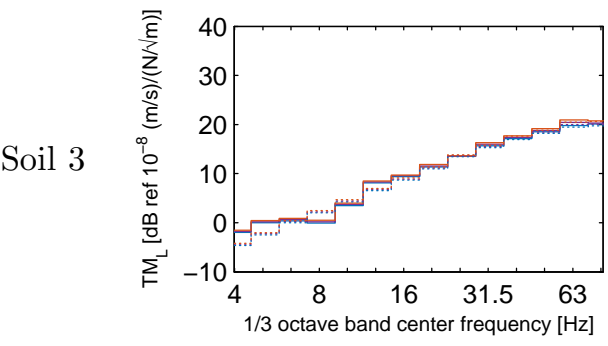

(f)
Strip foundation

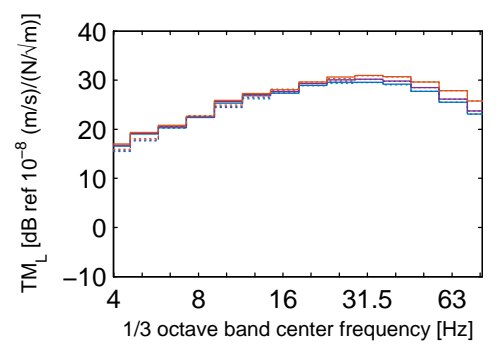

(a)

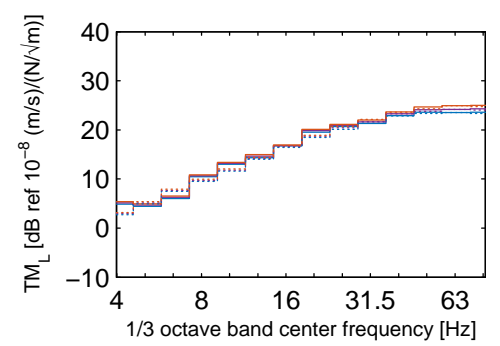

(d)

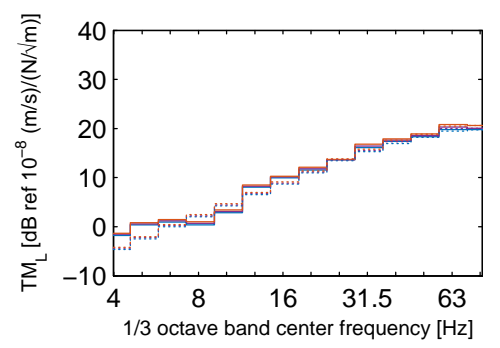

(g)
Raft foundation

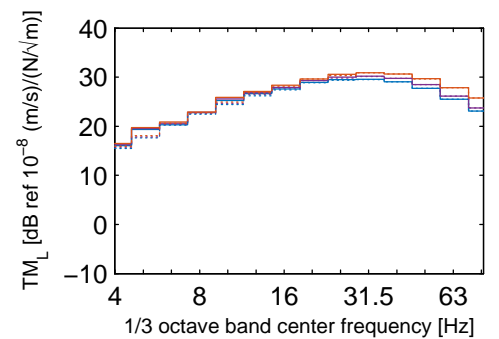

(b)

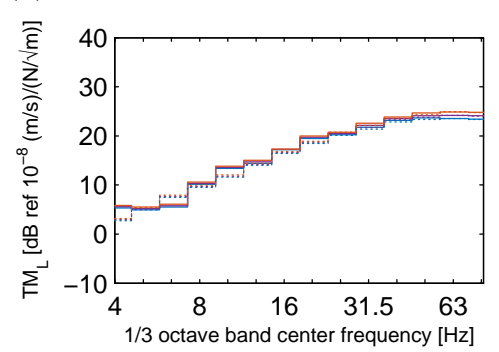

(e)

Figure 23: The line source transfer mobility for various soil properties and foundation types, with receivers on the ground surface at $1 \mathrm{~m}$ (blue line), $2 \mathrm{~m}$ (magenta line) and $3 \mathrm{~m}$ (red line) from the building. The solid line indicates the mobility level for receivers in the presence of the building and the dotted line indicates the mobility level for receivers in the free field (that is, with no building present).

source transfer mobility with the receiver $R_{\text {flex }}$ located at the mid-span of the floor (refer to figure 18) and the line source transfer mobility with the receiver $R_{\text {stiff }}$ located at a stiff location on the same floor. Figure 25] shows the mid-span amplification terms of the buildings for different soil properties and foundation types. The soil properties have a significant influence on the mid-span amplification terms over the entire frequency range of interest, of the order of $10 \mathrm{~dB}$. The FRA guidelines recommend a mid-span amplification factor of $6 \mathrm{~dB}$ in the fundamental floor resonance frequency range of $20-30 \mathrm{~Hz}$ for reinforced concrete slabs. For this model, a mid-span amplification of 5-8 dB is observed in the $31.5 \mathrm{~Hz}$ frequency band, regardless of soil or foundation type, which corresponds well with the FRA guideline. 
Reference foundation

Soil 1

Soil 2

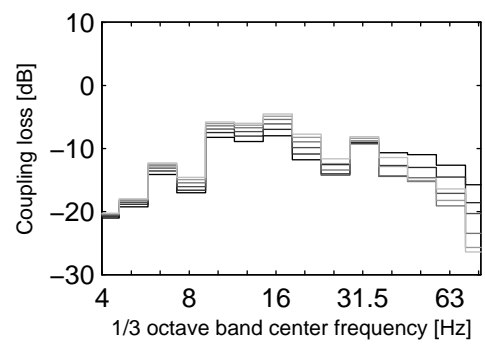

(c)

Soil 3

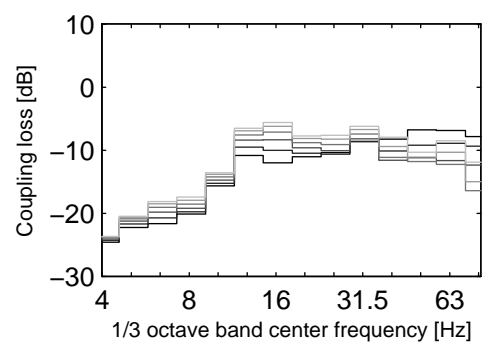

(f)
Strip foundation

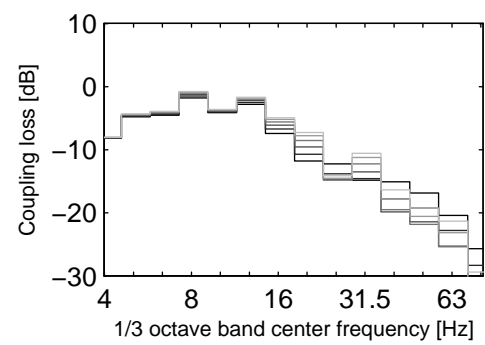

(a)

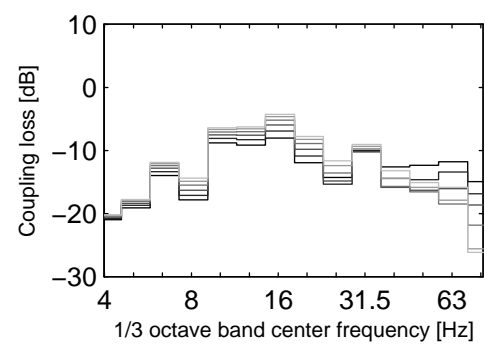

(d)

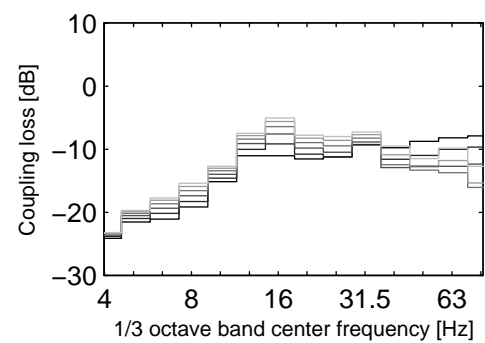

(g)
Raft foundation

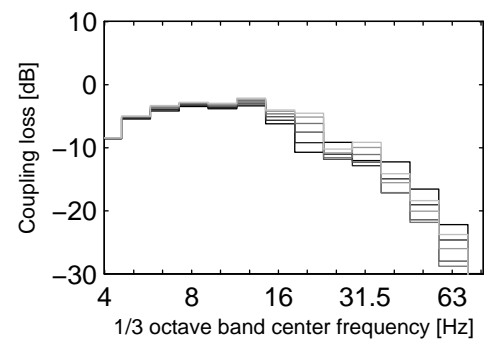

(b)

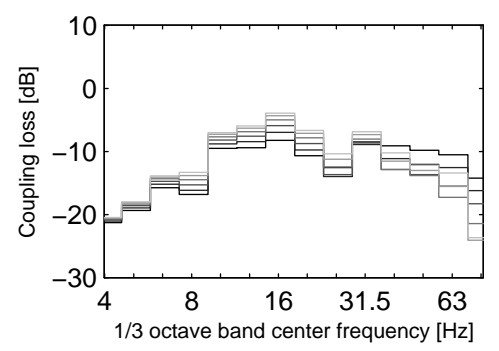

(e)

Figure 24: Coupling loss terms computed using $\mathbf{x}_{1}$ located $1 \mathrm{~m}$ from the building for receiver locations $R_{\text {stiff }}$ (figure 18). The floor level is indicated by the color of the line, where a lighter color corresponds to a higher floor level.

\subsubsection{Floor thickness}

The effect of floor thickness on the building's coupling loss is shown in figure 26. The difference in the response between the examined cases is limited. The maximum response is observed in the frequency band between $8 \mathrm{~Hz}$ and $16 \mathrm{~Hz}$. As the eigenfrequencies of the vertical modes of the floors shift to higher frequencies for increasing slab thickness, the maximum response in the coupling loss also shifts to higher frequencies. Floor-to-floor attenuation is only observed at frequencies above $31.5 \mathrm{~Hz}$ where it amounts to approximately $2 \mathrm{~dB}$ per floor level as given in the FRA guidelines. At frequencies between $8 \mathrm{~Hz}$ and $31.5 \mathrm{~Hz}$ the response generally amplifies between two consecutive floor levels. Below $8 \mathrm{~Hz}$, very little difference in the floor responses are observed.

Figure 27 shows the mid-span amplification for the buildings with different floor slab thickness. There 
Reference foundation

Soil 1

Soil 2

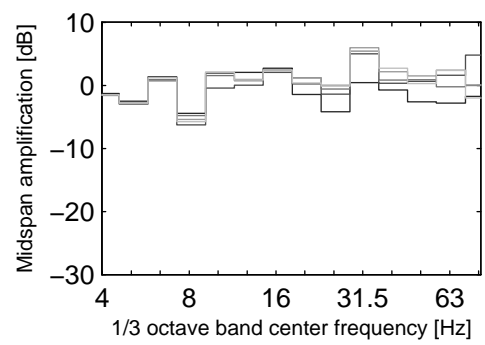

(c)

Soil 3

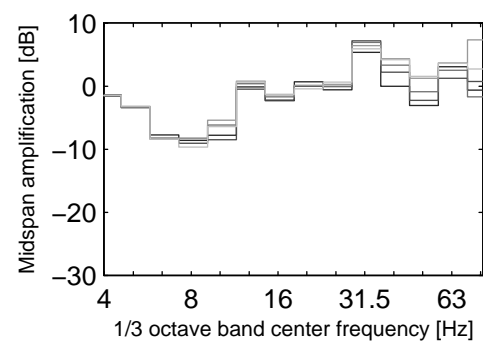

(f)
Strip foundation

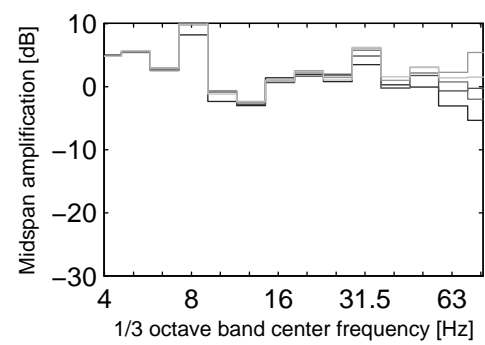

(a)

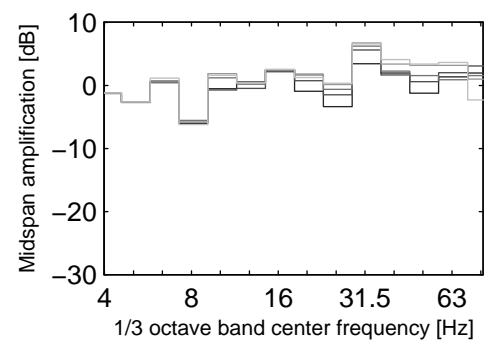

(d)

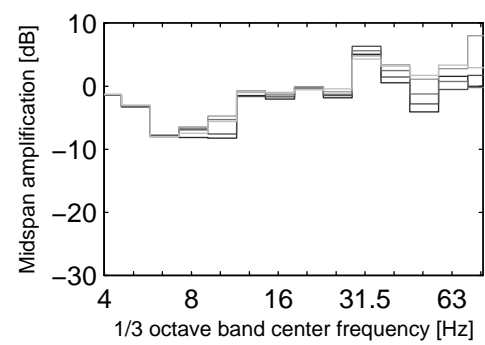

(g)
Raft foundation

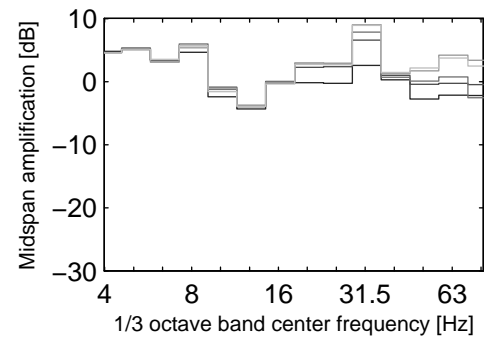

(b)

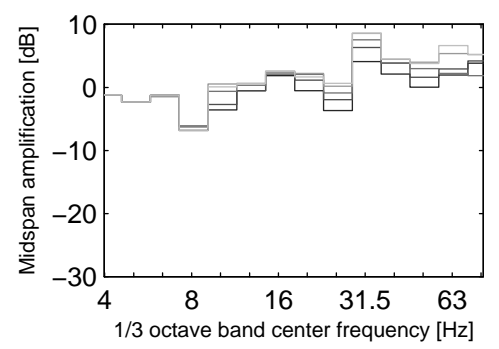

(e)

Figure 25: Mid-span amplification between the receiver locations $R_{\text {flex }}$ and $R_{\text {stiff }}$ (figure 18). The floor level is indicated by the color of the line, where a lighter color corresponds to a higher floor level.

is a small amount of variation in the mid-span amplification as the floor thickness increases. The amount of amplification varies considerably over frequency bands, and generally lies between $\pm 5 \mathrm{~dB}$.

\subsubsection{Building layout dimensions}

The influence of the building layout dimensions on the building's coupling loss terms is presented in figure 28. As the span lengths increase, the floor thickness and beam cross sections increase accordingly. The increased span lengths result in more flexibility, and the maximum building response can be seen to shift to a lower frequency. Figure 29 shows the mid-span amplification terms. There is a high degree of variation in these plots, making it difficult to draw conclusions about floor resonance effects. 


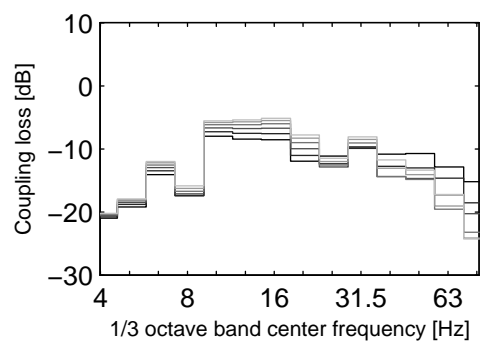

(a)

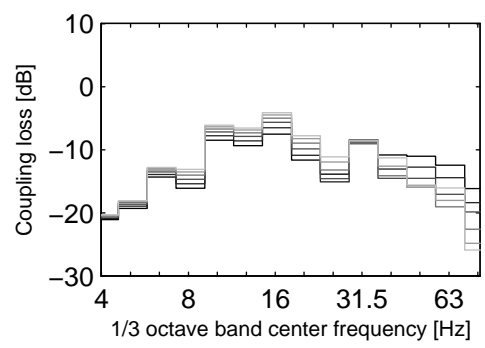

(c)

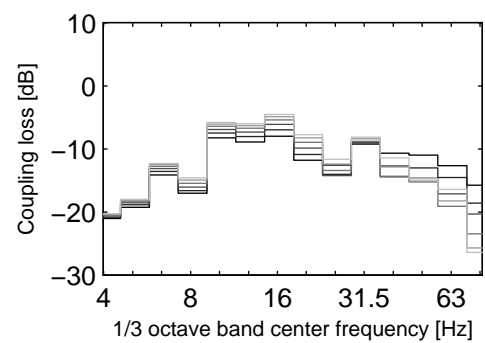

(b)

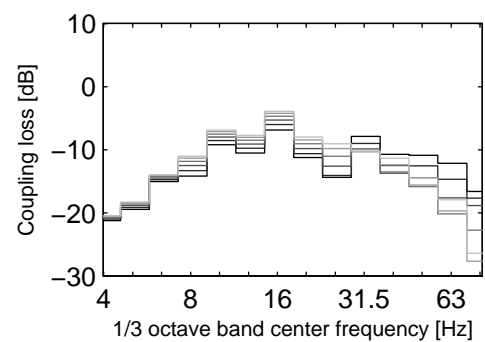

(d)

Figure 26: Influence of floor slab thickness on the coupling loss terms computed using $\mathbf{x}_{1}$ located $1 \mathrm{~m}$ from the building for

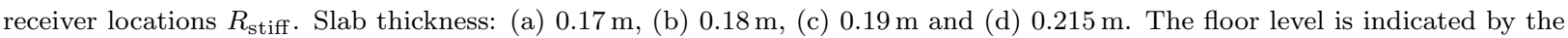
shade of the line, where a lighter shade corresponds to a higher floor level.

\subsubsection{Number of stories}

Figure [30 shows the coupling loss terms of the building with four, six and eight stories. The maximum response shifts to lower frequencies as the building height increases, and floor-to-floor amplification with increasing floor level is observed in the lower frequency range up to the frequency bands of $40 \mathrm{~Hz}, 31.5 \mathrm{~Hz}$ and $20 \mathrm{~Hz}$ for the 4-story, 6-story and 8-story building, respectively. The frequency band where the amplification changes to attenuation shifts to lower frequencies with increasing building height. Figure 31 presents the influence of the building height on the mid-span amplification terms. The difference between the examined cases is limited.

\section{Conclusions}

This paper has identified methods for quantifying the coupling loss of a building that is subject to groundborne vibration from a nearby railway. When both the railway and the building are present, the difference between vibration velocity levels at some point in the building and at some point in the free field can be used. When the building has not yet been constructed at the site of interest, free field vibrations in the absence of the structure can be used together with a numerical model of the building response. And when the railway has not been constructed at the site of interest, hammer excitations on or near the future track 


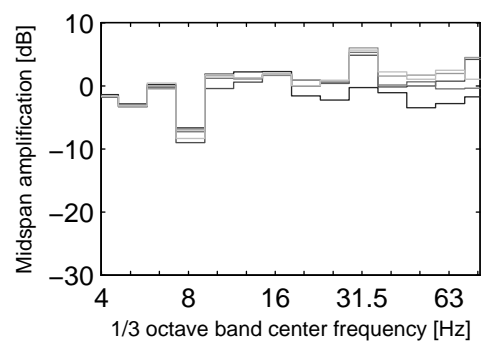

(a)

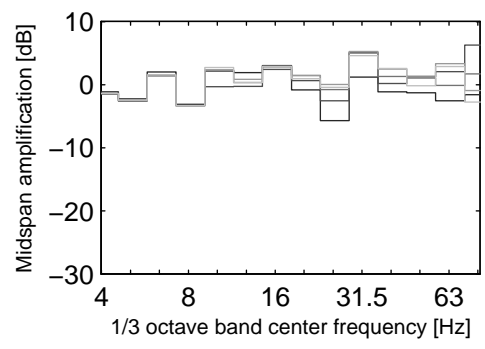

(c)

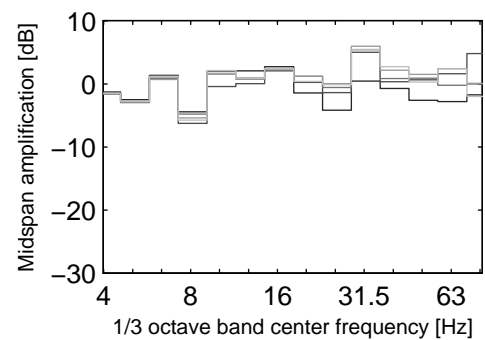

(b)

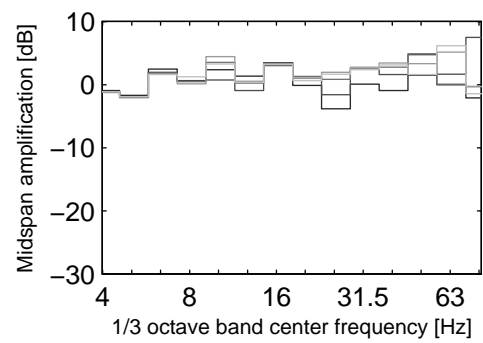

(d)

Figure 27: Influence of floor slab thickness on the mid-span amplification between the receiver locations $R_{\text {flex }}$ and $R_{\text {stiff }}$. Slab thickness: (a) $0.17 \mathrm{~m}$, (b) $0.18 \mathrm{~m}$, (c) $0.19 \mathrm{~m}$ and (d) $0.215 \mathrm{~m}$. The floor level is indicated by the shade of the line, where a lighter shade corresponds to a higher floor level.

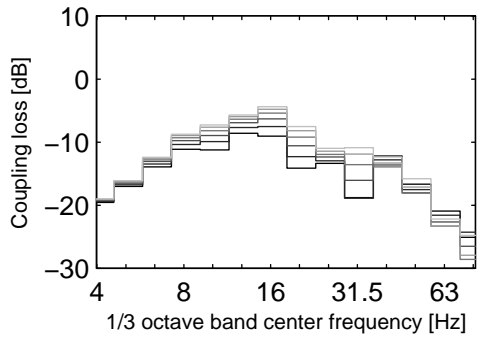

(a)

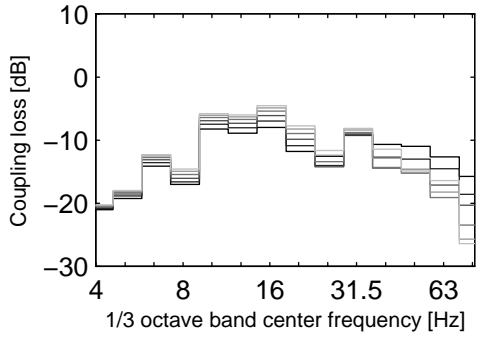

(b)

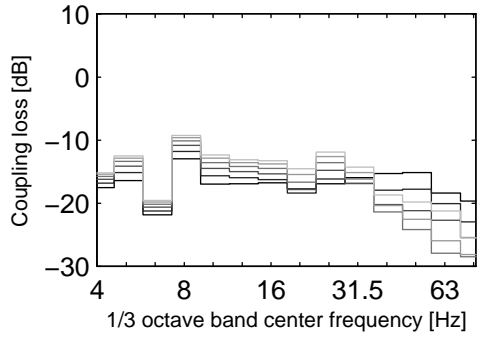

(c)

Figure 28: Influence of building layout dimensions on the coupling loss terms computed using $\mathbf{x}_{1}$ located $1 \mathrm{~m}$ from the building

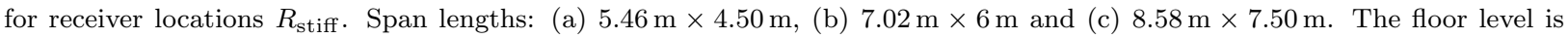
indicated by the shade of the line, where a lighter shade corresponds to a higher floor level.

location are employed. It has been shown using field measurements that the coupling loss values are not strongly affected by the use of hammer excitations instead of train passages. Both the field measurements and the modelling study have shown that the presence of the building attenuates the free field vibrations, resulting in negative coupling loss values, and that the coupling loss magnitude is sensitive to the location of the receivers within the building, with the greatest variation between floors occurring at above $16 \mathrm{~Hz}$. In addition, the amount of midspan amplification varies considerably over frequency bands and can reach up to 


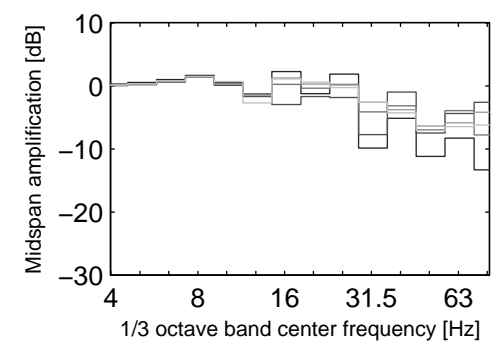

(a)

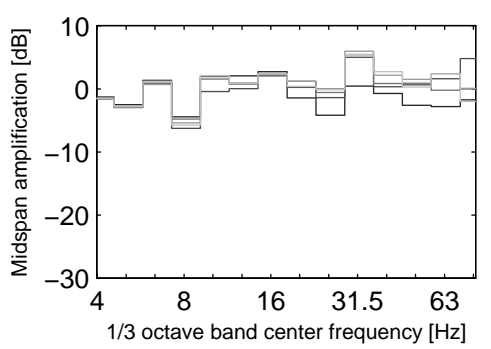

(b)

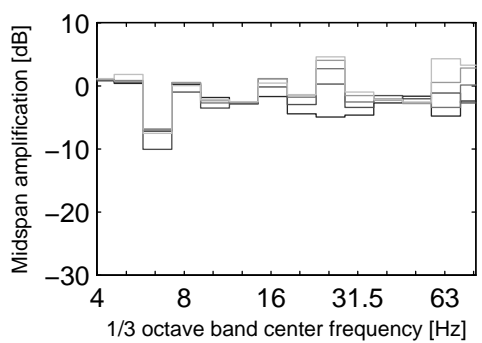

(c)

Figure 29: Influence of building layout dimensions on the mid-span amplification between the receiver locations $R_{\mathrm{flex}}$ and $R_{\text {stiff }}$. Span lengths: (a) $5.46 \mathrm{~m} \times 4.50 \mathrm{~m}$, (b) $7.02 \mathrm{~m} \times 6 \mathrm{~m}$ and (c) $8.58 \mathrm{~m} \times 7.50 \mathrm{~m}$. The floor level is indicated by the shade of the line, where a lighter shade corresponds to a higher floor level.

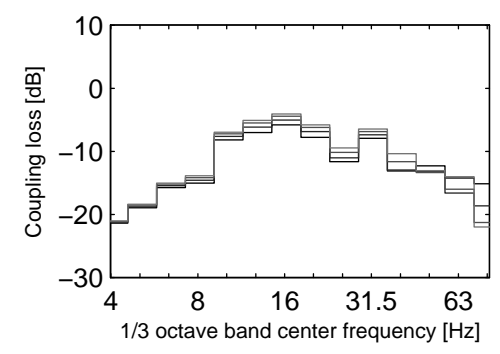

(a)

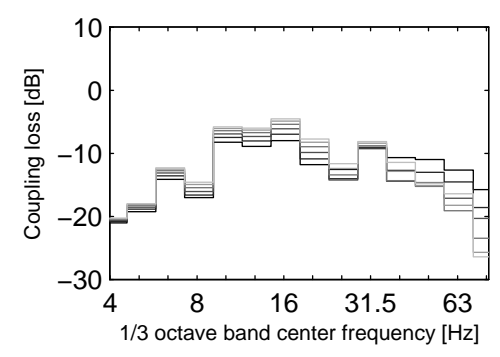

(b)

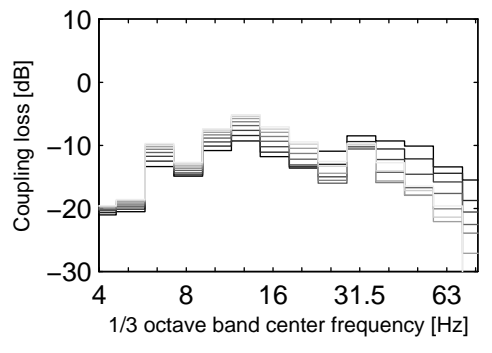

(c)

Figure 30: Influence of number of stories on the coupling loss terms computed using $\mathbf{x}_{1}$ located $1 \mathrm{~m}$ from the building for receiver locations $R_{\text {stiff }}$ (figure 18). Number of stories: (a) four, (b) six and (c) eight. The floor level is indicated by the shade of the line, where a lighter shade corresponds to a higher floor level.

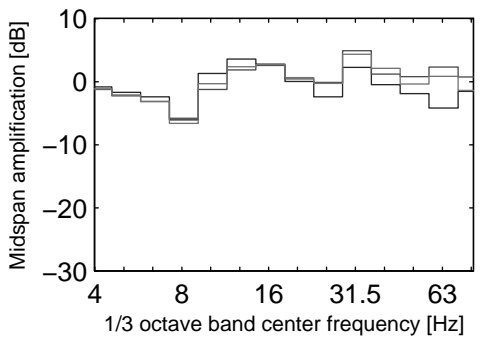

(a)

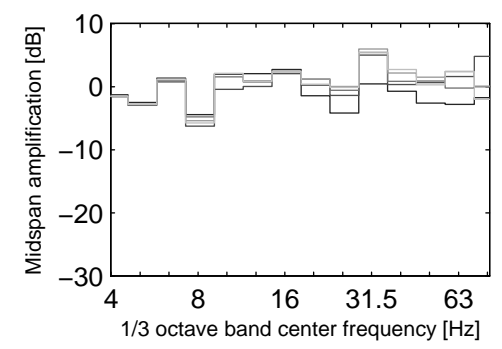

(b)

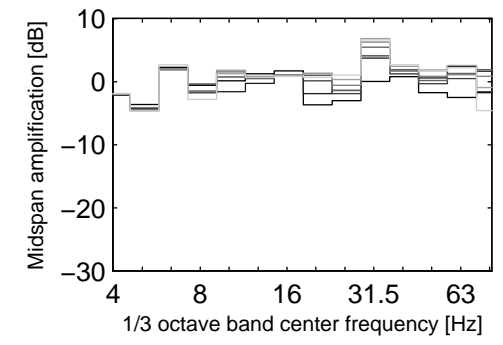

(c)

Figure 31: Influence of number of stories on the mid-span amplification between the receiver locations $R_{\mathrm{flex}}$ and $R_{\text {stiff }}$. Number of stories: (a) four, (b) six and (c) eight. The floor level is indicated by the shade of the line, where a lighter shade corresponds to a higher floor level.

$10 \mathrm{~dB}$ due to floor resonances. The results of the parametric study show that the soil type has a significant influence on the coupling loss, with the building geometry and foundation type having a lesser influence. 
The assumption that the source terms are independent of the propagation and receiver terms results in an approximate expression for the coupling loss that does not require a train passage and does not result in a loss of modelling accuracy. This means that simplified computational models that do not include a detailed railway structure can be employed, and also that the vibration response of the building can be determined by in situ measurements prior to railway construction. Practical guidelines for determining the coupling loss of a building using a minimum number of in situ measurements of train passages or transfer functions have been given. As both the computed and measured coupling loss values presented in this paper have been shown to differ significantly from the FRA adjustment factors, it is recommended that, wherever possible, vibration consultants seek to quantify the coupling loss using the methods herein.

\section{Acknowledgments}

The first author is a postdoctoral fellow of the Research Foundation Flanders (FWO). The support of FWO is gratefully acknowledged. The field measurement study presented in this paper was conducted as part of the project OT/13/059 "Quantifying and reducing uncertainty in structural dynamics" funded by the Research Council of KU Leuven. These measurements and some data processing were performed by Kristof Maes, Matthias Germonpré, Jie Zhang, and Avisek Mukherjee of the Department of Civil Engineering of KU Leuven. The parametric study was designed as part of the MSc thesis of Dieter Claesen of the Department of Civil Engineering of KU Leuven [21].

\section{References}

[1] G. Lombaert, G. Degrande, S. François, D. Thompson, Ground-borne vibration due to railway traffic, in: J. Nielsen, D. Anderson, P.-E. Gautier, M. Iida, J. Nelson, D. Thompson, T. Tielkes, D. Towers, P. de Vos (Eds.), Proceedings of the 11th International Workshop on Railway Noise, volume 126 of Notes on Numerical Fluid Mechanics and Multidisciplinary Design, Springer, Heidelberg, New York, Dordrecht, London, Uddevalla, Sweden, 2013, pp. 253-287. Invited state of the art paper.

[2] P. Coulier, G. Lombaert, G. Degrande, The influence of source-receiver interaction on the numerical prediction of railway induced vibrations, Journal of Sound and Vibration 333 (2014) 2520-2538.

[3] G. Kouroussis, L. van Parys, C. Conti, O. Verlinden, Prediction of ground vibrations induced by urban railway traffic: an analysis of the coupling assumptions between vehicle, track, soil and buildings, International Journal of Acoustics and Vibration 18 (2013) 163-172.

[4] M. Stupazzini, R. Paolucci, Ground motion induced by train passage in urban area, in: P. Sas, B. Bergen (Eds.), Proceedings of ISMA2010 International Conference on Noise and Vibration Engineering, Leuven, Belgium, pp. 3547-3558.

[5] W. Rücker, L. Auersch, A user-friendly prediction tool for railway induced ground vibrations: emission - transmission immision, in: 9th International Workshop on Railway Noise, Munich, Germany.

[6] K. Vogiatzis, Protection of the cultural heritage from underground metro vibration and ground-borne noise in athens centre: the case of the kerameikos archaeological museum and gazi cultural centre, International Journal of Acoustics and Vibration 17 (2012) 59-72. 
[7] H. Xia, J. Chen, P. Wei, C. Xia, G. De Roeck, G. Degrande, Experimental investigation of railway train-induced vibrations of surrounding ground and a nearby multi-story building, Earthquake Engineering and Engineering Vibration 8 (2009) 137-148.

[8] R. Hood, R. Greer, M. Breslin, P. Williams, The calculation and assessment of ground-borne noise and perceptible vibration from trains in tunnels, Journal of Sound and Vibration 193 (1996) 215-225.

[9] C. Madshus, B. Bessason, L. Hårvik, Prediction model for low frequency vibration from high speed railways on soft ground, Journal of Sound and Vibration 193 (1996) 195-203.

[10] C. Hanson, D. Towers, L. Meister, Transit noise and vibration impact assessment, Report FTA-VA-90-1003-06, U.S. Department of Transportation, Federal Transit Administration, Office of Planning and Environment, 2006.

[11] K. Kuo, H. Verbraken, D. G., G. Lombaert, Hybrid predictions of railway induced ground vibration using a combination of experimental measurements and numerical modelling, Journal of Sound and Vibration 373 (2016) 263-284.

[12] ISO 14837-1:2005 Mechanical vibration - Ground-borne noise and vibration arising from rail systems - Part 1: General guidance, International Organization for Standardization, 2005.

[13] H. Verbraken, Prediction of railway induced vibration by means of numerical, empirical, and hybrid methods, Ph.D. thesis, Department of Civil Engineering, KU Leuven, 2013.

[14] H. Verbraken, G. Lombaert, G. Degrande, Verification of an empirical prediction method for railway induced vibrations by means of numerical simulations, Journal of Sound and Vibration 330 (2011) 1692-1703.

[15] DIN 45672 Teil 2: Schwingungsmessungen in der Umgebung von Schienenverkehrswegen: Auswerteverfahren, Deutsches Institut für Normung, 1995.

[16] K. Kuo, G. Lombaert, G. Degrande, Quantifying uncertainties in measurements of railway vibration, in: D. Anderson (Ed.), Proceedings of the 12th International Workshop on Railway Noise, Terrigal, Australia, pp. 62-69.

[17] K. Kuo, G. Lombaert, G. Degrande, Characterisation of building response to railway induced vibration, in: J. Pombo (Ed.), Proceedings of the Third International Conference on Railway Technology: Research, Development and Maintenance, Cagliari, Sardinia, Italy.

[18] K. Kuo, G. Lombaert, G. Degrande, Quantifying dynamic soil-structure interaction for railway induced vibrations, in: F. Vestroni, F. Romeo, V. Gattulli (Eds.), Proceedings of the 10th International Conference on Structural Dynamics, EURODYN 2017, Rome, Italy, pp. 2372-2377.

[19] E. Kausel, Fundamental Solutions in Elastodynamics: A Compendium, Cambridge University Press, 2006.

[20] E. Kausel, J. Roësset, Stiffness matrices for layered soils, Bulletin of the Seismological Society of America 71 (1981) 1743-1761.

[21] D. Claesen, The response of various building designs to railway induced vibrations, Master's thesis, Department of Civil Engineering, KU Leuven, 2018. 